\title{
Geradores elétricos monofásicos e trifásicos como suporte didático para o ensino de Eletromagnetismo
}

André Luíz Alves ${ }^{1}$

Departamento de Ciências Naturais - Universidade Federal do Espírito Santo

São Mateus - ES

Yohannes Beninca Moreira Motta ${ }^{1}$

Licenciando em Física - Universidade Federal do Espírito Santo

Antônio Carlos Barbosa Zancanella ${ }^{1}$

Instituto Federal do Espírito Santo

São Mateus - ES

\section{Resumo}

A energia elétrica é de fundamental importância para o mundo moderno pois é fonte de luz, calor e força motriz de todas as máquinas e equipamentos eletroeletrônicos. Buscando mostrar a importância da fisica no cotidiano dos estudantes, propõe-se neste trabalho a construção e estudo de geradores elétricos de corrente alternada dos tipos monofásicos e trifásicos. O estudante ao se deparar com este experimento identificará a importância da lei de Faraday para a compreensão do funcionamento dos geradores. Foi possível entender a partir desta lei, a conexão entre as bobinas e a disposição dos ímãs nos sistemas estudados. Foram construídos gráficos para investigar a relação entre a frequência da onda gerada e a frequência de rotação do gerador, e também, a relação entre a tensão eficaz e a frequência de rotação. Em especial, no sistema trifásico foi possivvel compreender por meio de ilustrações, as conexões entre as bobinas para geradores com seis ou mais bobinas nas ligações do tipo estrela e triângulo. O aparato experimental é de grande praticidade, fácil de ser construído, de ser montado e desmontado. O custo médio foi em torno de $R \$ 300,00$, o qual varia com a quantidade de sistemas construídos.

\footnotetext{
${ }^{+}$Single-phase and Three-phase Electric Generators as a Didactic Support to Electromagnetism Teaching

* Recebido: março de 2020. Aceito: maio de 2020.

1 E-mails: andluial@yahoo.com.br; benica.yoyo@gmail.com; antonio.zancanella@ifes.edu.br
} 
Palavras-chave: Geradores elétricos; Ensino; Lei de Faraday; Monofásico; Trifásico.

\begin{abstract}
Electric energy is of fundamental importance to the modern world because it is a source of light, heat and driving force of all electronic machines and equipment. Aiming to show the importance of physics in the students' daily life, this work proposed the construction and study of single-and three-phase alternating current electric generators. When faced with this experiment, the student will realize how important Faraday's law is for understanding the operation of generators. It was possible to understand from this law, the connection between the coils and the arrangement of the magnets in the studied systems. Graphs were constructed to investigate the relationship between the generated wave frequency and the generator rotation frequency and the relationship between the effective voltages and the rotation frequency. In particular, in the three-phase system it was possible to understand through illustrations the connections between coils for generators with six or more coils in star and triangle connections. The experimental apparatus is very practical, easy to build and to be assembled and disassembled. The average cost was around $R \$: 300.00$, but it depends on the number of systems assembled.
\end{abstract}

Keywords: Electric Generators; Teaching; Faraday's Law; Singlephase; Three-phase.

\title{
I. Introdução
}

Ao considerar o cenário atual da educação no Brasil, depara-se com o distanciamento entre o que a escola deveria proporcionar ao aluno e o que ela realmente oferece. Os educadores precisam buscar novos caminhos, para que seja possível transformar suas práticas, oportunizando a participação ativa/reflexiva do aluno na aquisição de conhecimentos, estimulando-o a pensar, levantar hipóteses, pesquisar, confrontar ideias, avaliar resultados e reavaliar suas concepções dentro e fora do âmbito escolar (MELO, 2015; COSTA, 2016; BARROSO, 2018).

A apresentação de experiências em sala de aula facilita a diminuição da barreira que existe no aprendizado de todas as áreas da ciência, e faz com que os alunos adquiram um novo comportamento. Estes tornam-se mais interessados e participativos no ambiente escolar e o trabalho do professor fica mais agradável e produtivo (AZEVEDO, 2017; ALVES, 2019). 
Neste trabalho, a prática experimental para o ensino da geração da energia elétrica alternada foi utilizada, com o objetivo de mostrar a importância do eletromagnetismo no cotidiano dos alunos e, com a intenção de tornar a física mais significativa para eles.

A energia elétrica é uma das maiores conquistas da humanidade devido as suas infindáveis utilidades. Estritamente ligada aos avanços tecnológicos dos últimos séculos, esta se mostra de extrema importância para a sociedade moderna. Equipamentos eletroeletrônicos como computador, televisão, aparelhos de som, aquecedores e diversos outros, só existem graças à energia elétrica: a capacidade de uma corrente elétrica realizar trabalho (LARA, 2014). Sua natureza surge quando um campo elétrico é estabelecido em um condutor ou semicondutor, o que permite o movimento de cargas elétricas de uma região de maior para o menor potencial elétrico, ou vice-versa, dependendo se a natureza das cargas é positiva ou negativa. Assim, a energia potencial das cargas é convertida em energia térmica, luminosa, mecânica, dentre outras.

As tecnologias atuais surgiram ao longo de vários séculos, conforme se pesquisava e entendia a passagem da corrente elétrica em meios materiais. Vale a pena destacar, a observação feita por Oersted em 1819 no qual a passagem da corrente elétrica em um condutor produz um campo magnético. Essa foi uma descoberta crucial na história da física, dando origem ao eletromagnetismo (YOUNG, 2009). Com base neste experimento, foi possível a construção dos primeiros eletroímãs e motores elétricos em corrente contínua.

Outra descoberta fascinante foi feita por Faraday e Henry, em meados de 1830, ao observar que o movimento relativo entre ímãs e bobinas produz nos terminais destas uma força eletromotriz (fem). Surge de início, a possibilidade do uso desse fenômeno na construção de geradores de energia elétrica do tipo corrente alternada. Foi o grande inventor Nikola Tesla que contribuiu decisivamente para mostrar que a tensão alternada, na configuração trifásica, é a forma mais segura, econômica e prática de ser produzida e consumida (JONES, 2004). A tensão alternada é produzida quando o rotor de um gerador é movimentado por quedas d'água (hidrelétricas), ventos (eólica), queima do gás natural para gerar vapor (termelétrica) e as que utilizam a divisão do núcleo atômico em reatores (nuclear). Ao girar, o fluxo do campo magnético de ímãs acoplados no rotor é variado, produzindo fem (tensão) de acordo com a lei de Faraday.

Estudos têm demonstrado que o aluno, ao estudar conteúdos de eletricidade e magnetismo, apresenta dificuldades para compreender figuras, imagens e simbologias e, consequentemente, entender teorias e o funcionamento de certos dispositivos (DIAS, 2009; MOREIRA, 2017). Apesar da existência de excelentes conjuntos didáticos disponíveis no mercado, verifica-se que, além do alto custo, em muitos casos os kits são simples e distantes da realidade dos estudantes. Muitas vezes as partes dos componentes se encontram encapsuladas em invólucros, o que não permite a visualização dos detalhes relevantes ao entendimento do seu funcionamento (RECHE, 2013). 
Diante disso, propõe-se neste trabalho, a construção de geradores elétricos monofásicos e trifásicos com ímãs permanentes como material didático para o ensino de eletromagnetismo. Foram explorados a conexão das bobinas, a relação entre a frequência de rotação (frequência mecânica), a frequência elétrica e a dependência da tensão eficaz gerada com a frequência mecânica. Especificamente no sistema trifásico, foi explorada a relação entre tensão de fase e tensão de linha nas ligações do tipo estrela e triângulo entre as bobinas. $\mathrm{O}$ aparato experimental é de baixo custo e muito simples de ser reproduzido em laboratório. Neste primeiro momento, o gerador foi analisado em aberto, sem nenhuma conexão com qualquer fonte externa.

\section{Abordagem teórica}

\section{II.1 Geradores com Î́mãs Permanentes de Fluxo Axial}

Nas máquinas elétricas do tipo geradores de tensão alternada, a polaridade da tensão alterna em uma determinada frequência entre positiva e negativa, quando o fluxo de um campo magnético atravessa um conjunto de bobinas. A principal vantagem no uso desta tensão está na transmissão a longas distâncias: quando a tensão é elevada por meio de um transformador, ocorre um decréscimo de corrente, oferecendo menor perda energética por efeito Joule. Quando necessário, os valores de tensão e corrente podem ser drasticamente reduzidos, o que possibilita o uso em equipamentos eletrônicos.

Os geradores elétricos podem ser dos tipos síncronos e assíncronos, sendo que o primeiro opera com uma velocidade de rotação sincronizada com a frequência da tensão elétrica alternada gerada. Já o segundo tipo não há um sincronismo deste tipo. Podem ainda ser classificados de acordo com a forma com que o fluxo magnético atravessa as bobinas do gerador, em radial ou axial. No primeiro, o fluxo do campo magnético é perpendicular ao eixo de rotação; já no segundo o fluxo é paralelo ao eixo (MAIA, 2011). Este campo pode ser produzido por ímãs permanentes ou pode ser produzido por uma bobina tipo eletroímã, cuja corrente inicial em seus enrolamentos (corrente de excitação), é fornecida por uma fonte externa. Uma vez que o gerador está em funcionamento, a corrente nesta bobina pode ser alimentada pelo próprio gerador (CARVALHO, 2011). A maior vantagem do uso de geradores de ímãs permanentes é que se torna desnecessário o uso de uma fonte de excitação externa para produzir a corrente inicial no eletroímã, reduzindo custos. Adicionalmente, não há perdas por efeito Joule no eletroímã, o que aumenta a eficiência do gerador (WESCHENFELDER, 2012).

Materiais ferromagnéticos como o ferro-silício (Fe-Si) são utilizados para maximizar o campo magnético nos núcleos das bobinas. Estes se encontram em formas de lâminas, evitando as chamadas correntes parasitas. Ainda, a configuração dos imãs no rotor que reforçam as linhas de campo magnético é tal que eles sejam alternados em norte e sul (MAIA, 2011; WESCHENFELDER, 2012). Os geradores didáticos aqui produzidos são do tipo 
síncrono de ímãs permanentes de fluxo axial, comuns em geradores eólicos (MAIA, 2011). Para maior praticidade e facilidade de reprodução dos geradores didáticos neste trabalho, estes foram montados em peças de madeira com apenas um rotor.

Na Fig. 1(a) estão ilustrados os componentes básicos de um gerador de fluxo axial do tipo Torus NN e, na parte (b), uma visão lateral (direita para a esquerda, ou vice-versa) para um sistema com dois ímãs e duas bobinas. O gerador Torus é composto de dois rotores, que giram juntos através de um eixo (não ilustrado nesta Figura) e um estator com as bobinas de fios de cobre esmaltado, que ficam estáticas entre os rotores (LENZ, 2013). A quantidade de ímãs fixados nos rotores 1 são iguais ao do rotor 2 e estão em polaridades Norte (N) e Sul (S) adjacentes alternadas para maximizar o fluxo do campo magnético.
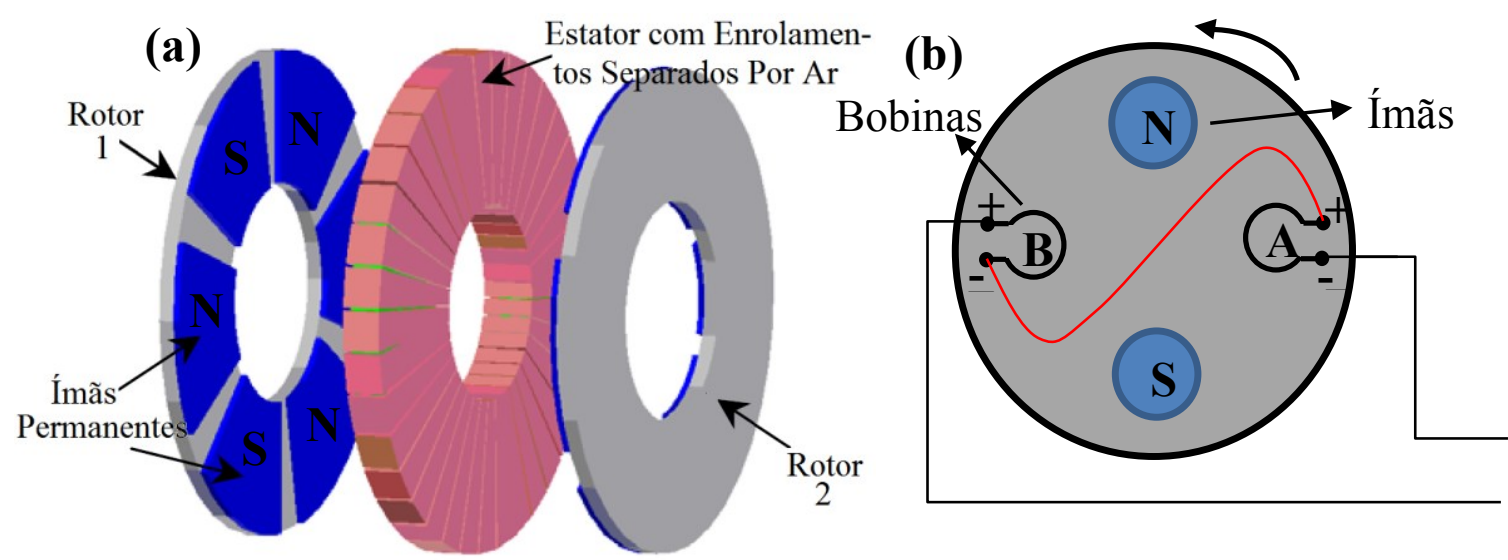

Fig. 1- (a) Ilustração das partes de um gerador de fluxo axial. Os ímãs em azul, com polaridades Norte (N) e Sul (S) estão fixados nos rotores 1 e 2. Na parte central ficam as bobinas, enroladas no estator. (b) Ilustração da vista lateral do gerador na configuração monofásica. O rotor em sinza, gira por cima das bobinas $A$ e $B$, fixas no estator e, conectadas pelo fio em vermelho. Os sinais (+) e (-) representam a polaridade da tensão nos extremos das bobinas quando o estator gira no sentido anti-horário. (a) Fonte: Lenz (2013). (b) Fonte: Acervo do Autor.

A Fig. 1(b) ilustra a forma geométrica dos ímãs, bobinas e estator construídos neste trabalho. As bobinas A e B, imóveis e fixas no estator, são representadas com círculos abertos e os ímãs, na parte superior com faces alternadas de polos $\mathrm{N}$ e $\mathrm{S}$, pelos círculos em azul. Tanto as bobinas, quanto os ímãs estão defasados de um ângulo de $180^{\circ}$. O rotor, ao girar no sentido anti-horário, por exemplo, fará com que faces distintas dos ímãs passem sobre bobinas, produzindo fluxos de campo em sentidos opostos sobre elas. Assim, de acordo com a lei de Faraday/Lenz, quando o campo magnético produzido pelo polo $\mathrm{S}$ do ímã atravessar a bobina A, a fem é tal que o conector superior desta bobina estará no maior potencial $(+)$ e o conector inferior, no menor potencial (-). 
De forma semelhante, quando o polo $\mathrm{N}$ do ímã passar por cima da bobina $\mathrm{B}$, o conector superior estará no potencial $(+)$ e o inferior no potencial (-). Assim, vale a pena lembrar ao estudante que da mesma forma com que se ligam pilhas em série, as bobinas do gerador também devem ser ligadas. Esta ligação é ilustrada na Figura 1(b) por meio da linha vermelha: conector com potencial (+) ligado ao conector com potencial (-). A polaridade desta tensão irá inverter em cada bobina, quando o polo $\mathrm{N}$ passar pela bobina $\mathrm{A}$ e o $\mathrm{S}$ pela bobina B. Assim, a tensão nos fios que saem das bobinas oscilará no tempo, alternando entre positiva e negativa. Esse tipo de gerador de tensão alternada é conhecido como monofásico. Um exemplo de tensão alternada é a senoidal, que pode ser descrita pela equação:

$$
V(t)=V_{m} \operatorname{sen}(\omega t+\phi),
$$

no qual: $V_{m}$ é a amplitude da tensão;

$\omega=2 \pi f$ é a frequência angular em $\mathrm{rad} / \mathrm{s}$ e fé a frequência em $\mathrm{Hz}$;

$\phi$ é o ângulo de fase.

Considerando que o valor médio em um período (T) da Equação (1) é nulo, define-se o valor eficaz ou Root Mean Square (RMS) como:

$$
\begin{gathered}
V_{R M S}=\sqrt{\frac{1}{T} \int_{0}^{T} v(t)^{2} d t} \\
V_{R M S}=\frac{V_{m}}{\sqrt{2}}
\end{gathered}
$$

A obtenção da Equação (3), a partir da Equação (2) pode ser vista em maiores detalhes em MARKUS, 2004. Assim, $V_{R M S}$ é equivalente a um valor de tensão contínua que dissipa, em uma resistência, a mesma quantidade de energia num período de tempo (NAKASHIMA, 2019).

\section{II.2 Relação entre frequências}

No sistema discutido anteriormente, a tensão elétrica completará um ciclo quando o polo norte passar por uma das bobinas e retornar na mesma bobina, ou seja, para uma rotação de $360^{\circ}$. Nessa condição a frequência do rotor, chamada de frequência mecânica $\left(\mathrm{f}_{\mathrm{m}}\right)$, é igual à frequência com que os ímãs passam pelas bobinas, a denominada frequência elétrica $\left(f_{\mathrm{el}}\right)$. A distinção entre essas frequências ocorre quando, por exemplo, se dobra a quantidade de ímãs no rotor. Para esse caso, o valor da $f_{\mathrm{el}}$ é duplicada em relação a $f_{m}$, quando essas são medidas em rotações por minuto (RPM). Uma verificação na Figura 2(a) ajudará o estudante a compreender este exemplo específico: quando o rotor gira de $360^{\circ}$, o polo norte atravessará a bobina $\mathrm{A}$, ou $\mathrm{B}$, duas vezes. Para um número $N$ total de polos, a relação entre $\mathrm{f}_{\mathrm{m}}$ e $\mathrm{f}_{\mathrm{el}}$, medidas em RPM, em geradores síncronos é dada pela Equação (4). Para medições em Hertz, basta trocar o fator 2 por 60 nesta equação (MAIA, 2011).

$$
f_{e l}=\frac{N}{2} f_{m}
$$


Para tornar o gerador mais eficiente, o espaço no rotor deve ser aproveitado ao máximo, por meio da adição de mais polos e mais bobinas (NIEDERLE, 2018). As linhas de campo magnético serão reforçadas e o fluxo magnético nas bobinas aumentará. Tendo em vista que a magnitude da tensão eficaz $\left(\mathrm{V}_{\mathrm{RMS}}\right)$ é proporcional a $\mathrm{f}_{\mathrm{el}}$, o aumento do número de polos fará com que a $V_{\text {RMS }}$ também aumente. Assim, não são necessários altos valores de $f_{m}$. Isto pode ser observado, por exemplo, nos geradores eólicos, quando se percebe a baixa velocidade da rotação mecânica das hélices. Outro exemplo é a usina hidrelétrica de Itaipu, cujo gerador possui $\mathrm{N}=80$ polos e $\mathrm{f}_{\mathrm{m}}=90 \mathrm{RPM}(1,5 \mathrm{~Hz})$ resultando em $\mathrm{f}_{\mathrm{el}}=3600 \mathrm{RPM}=60$ $\mathrm{Hz}$.

Na Fig. 2(b) está esquematizado um gerador monofásico com $\mathrm{N}=4$ polos e 4 bobinas. O estudante pode verificar através da lei de Lenz a polaridade entre as bobinas e, também, a ligação em série entre elas, simbolizadas pelas linhas vermelhas.

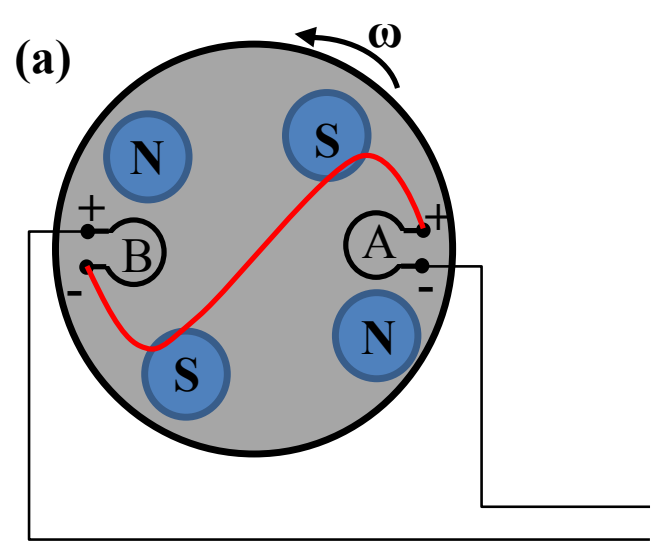

(b)

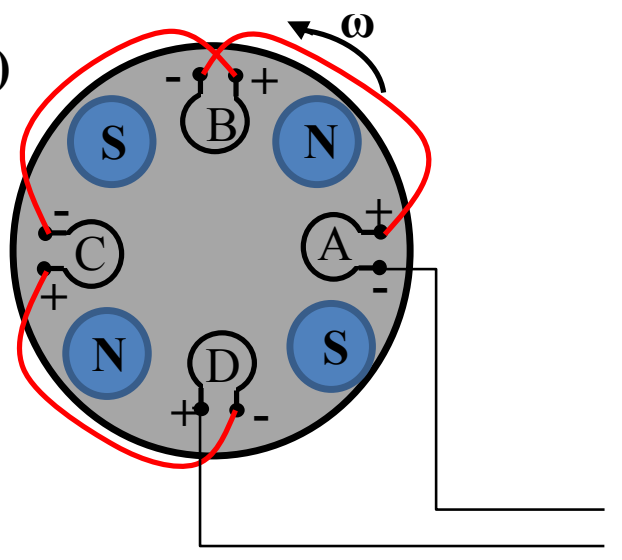

Fig. 2 - Em (a) uma Ilustração de um gerador monofásico de 4 polos e duas bobinas. Em (b) um gerador de 4 polos e 4 bobinas. Em ambos os geradores as ligações pelo fio em vermelho, favorece a máxima tensão gerada. Fonte: Acervo do autor.

\section{II.3 Sistemas trifásicos}

Os geradores trifásicos são caracterizados por produzirem tensões alternadas dos tipos senoidais balanceadas e defasadas em $120^{\circ}$ entre si. Considerando um modelo ideal, as tensões elétricas produzidas terão a forma (SADIKU, 2013):

$$
\begin{gathered}
V_{A}(t)=V_{A m} \operatorname{sen}(\omega t) \\
V_{B}(t)=V_{B m} \operatorname{sen}(\omega t+120) \\
V_{C m}(t)=V_{C m} \operatorname{sen}(\omega t-120),
\end{gathered}
$$

nos quais $V_{A m}=V_{B m}=V_{C m}=V_{m}$ são as amplitudes da tensão nas bobinas $\mathrm{A}$, B e C respectivamente; $V_{A}(t)=V_{A m}$ para $\mathrm{t}=0 \mathrm{~s}$. 
O sistema trifásico, por apresentar diversas vantagens sobre os sistemas monofásicos e polifásicos, tornou-se padrão na produção da energia elétrica no mundo. Por exemplo, na questão da transmissão, são requeridos condutores com diâmetros menores que o sistema monofásico para geradores de mesma potência. Com a tensão trifásica, é possível produzir motores elétricos menores, mas de potência igual ou superior aos monofásicos. Outra vantagem é que a potência fornecida por este sistema, ao contrário dos monofásicos é constante (AZEVEDO, 2017).

Na Fig. 3(a) está ilustrado um gerador axial do tipo trifásico. As bobinas A, B e C, defasadas de $120^{\circ}$, geram tensões elétricas que também são defasadas de $120^{\circ}$, quando os ímãs com polaridades $\mathrm{N}$ e $\mathrm{S}$ passam sobre estas, descrevendo um movimento circular com frequência angular, $\omega$. $\mathrm{O}$ diagrama de fasores para este sistema está ilustrado na Fig. 3(b). As Equações (5)-(7) podem ser obtidas a partir deste diagrama, nos quais os módulos dos fasores são iguais às suas amplitudes. Conforme os fasores giram, no sentido anti-horário, suas projeções no eixo y fornecem as Equações (5)-(7). O estudante pode verificar que a soma fasorial das tensões nas três bobinas é nula. Assim, ao ligar as mesmas saídas das bobinas (por exemplo, as extremidades esquerdas) resultará em uma tensão nula. O fio que sai desta ligação, denomina-se neutro (n) e a diferença de potencial elétrico com relação à Terra é, teoricamente, nulo.
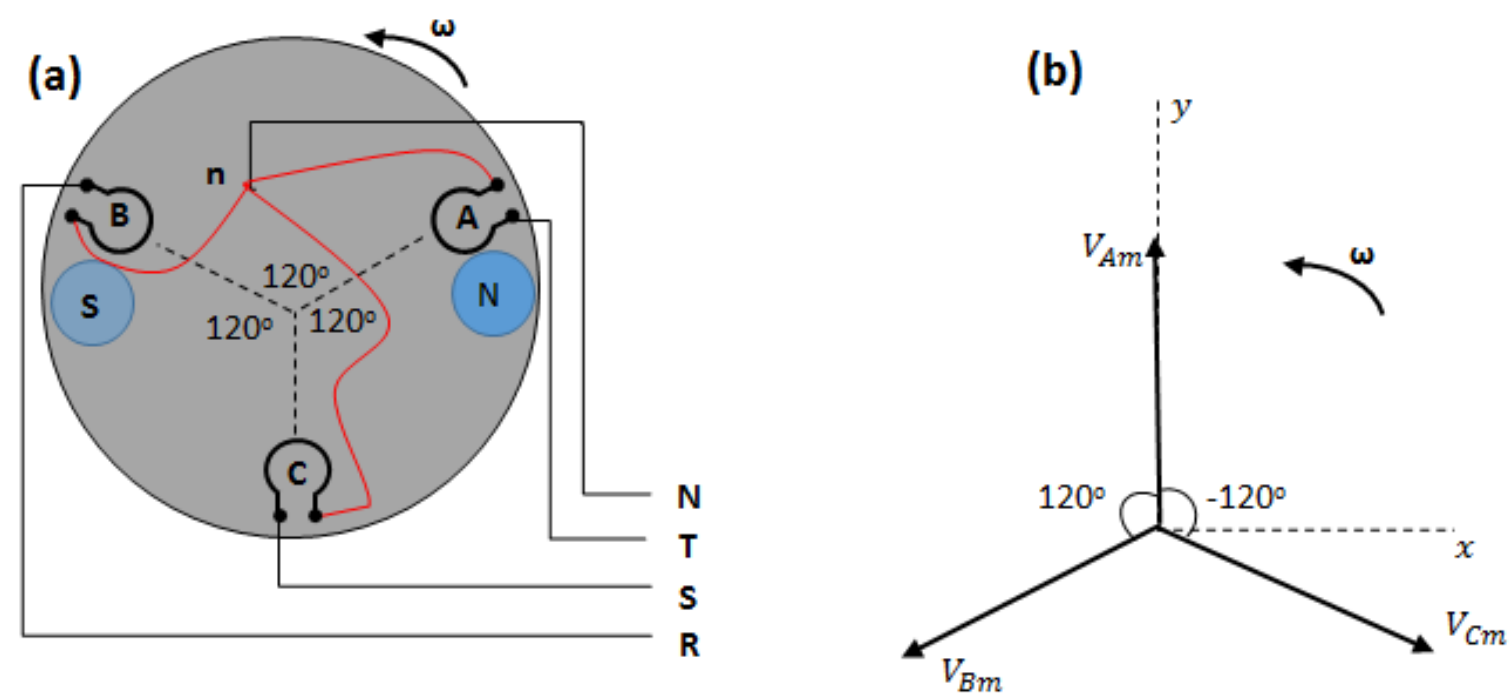

Fig. 3 - (a) Ilustração de um gerador trifásico com as bobinas A, B e C defasadas geometricamente de $120^{\circ}$ e os ímãs com polaridades opostas em $180^{\circ}$. Devido a esta configuração, as tensões em cada bobina estarão defasadas de $120^{\circ}$ quando o rotor (cinza) estiver girando. A soma fasorial destas tensões é nula de tal forma que é possível conectar as bobinas pelos fios em vermelho, gerando o fio neutro (n). Os três fios que saem das bobinas são chamados de fases e indicados por $R, S$ e T. Em (b), um diagrama fasorial para o sistema em (a). Cada fasor com módulos $V_{A m}$, $V_{B m}$ e $V_{C m}$ gira com frequência angular $\omega$, no sentido anti-horário. Fonte: Acervo do autor. 
A ligação trifásica no qual se obtém o neutro é denominada de estrela, ou ' $\mathrm{Y}$ '. Os demais fios, comumente denominado por $\mathrm{R}, \mathrm{S}$ e $\mathrm{T}$ são chamados de fases e as tensões medidas em relação ao neutro, chamadas de tensão de fase $\left(\mathrm{V}_{\mathrm{F}}\right)$ variam de acordo com as equações apresentadas em (5)-(7). Por outro lado, a diferença de potencial entre qualquer uma das fases, denominada de tensão de linha $V_{L}$, é também uma função que oscila no tempo com a mesma frequência $\omega$, porém com amplitude dada por $\sqrt{3} V_{m}$. Na Fig. 4, está representado, como exemplo, a diferença entre os fasores de tensão $V_{C m}-V_{B m}=V_{L}$. Assim, como se adiciona vetores, o módulo da diferença entre estes fasores é:

$$
\begin{gathered}
V_{L}=\sqrt{V_{m}^{2}+V_{m}^{2}+2 V_{m}^{2} \cdot V_{m}^{2} \cdot \cos 60^{\circ}} \\
V_{L}=\sqrt{3} \cdot V_{m}
\end{gathered}
$$

Em termos de valores eficazes (RMS):

$$
V_{L}^{R M S}=\sqrt{3} \cdot V_{F}^{R M S} \approx 1,73 \cdot V_{F}^{R M S}
$$

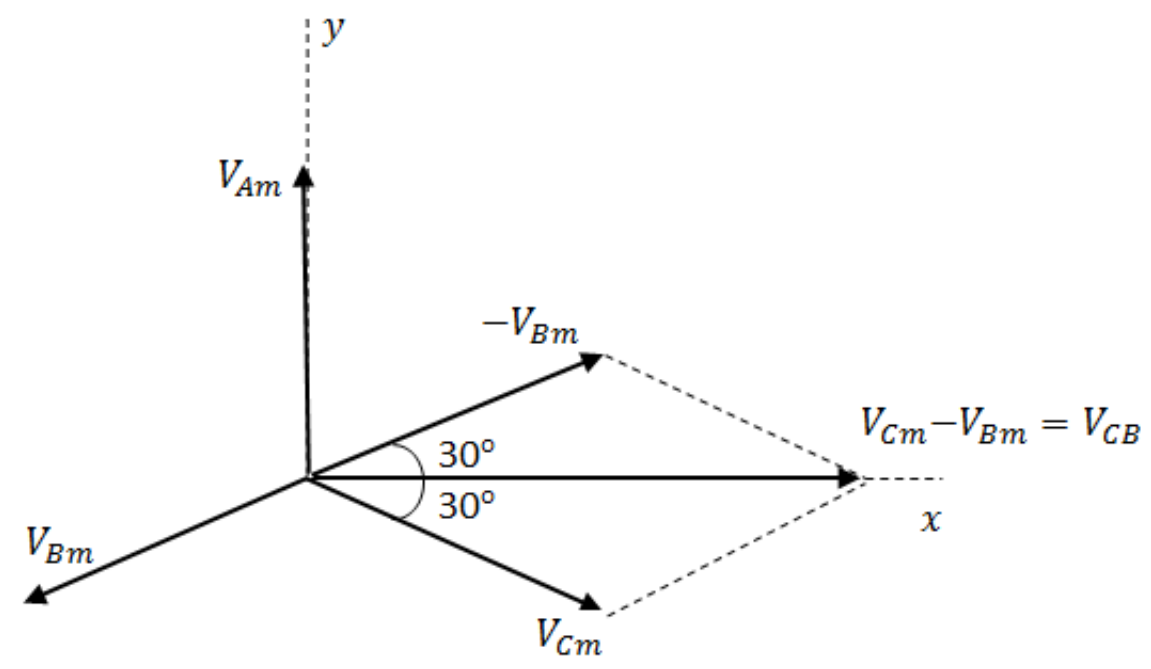

Fig. 4 - Representação do negativo do fasor de tensão na bobina B (- $\left.V_{B m}\right)$. Este fasor foi adicionado ao fasor $V_{C m}$ para a obteção do fasor soma $V_{C m}-V_{B m}$. Fonte: Acervo do autor.

Assim como no sistema monofásico, no sistema trifáfico um número maior de ímãs e bobinas é ultilizado visando aumentar a eficiência do gerador e torná-lo um projeto de fato (NIEDERLE, 2018). Outro tipo de ligação entre as bobinas é a do tipo delta ( $\Delta$ ) (SADIKU, 2013). Na Fig. 5(a) e (b) estão ilustradas, para comparação, as ligações do tipo Y e $\Delta$, empregadas em geradores trifásicos. O estudante pode observar que na ligação do tipo $\Delta \mathrm{a}$ tensão de fase é igual à tensão de linha. 


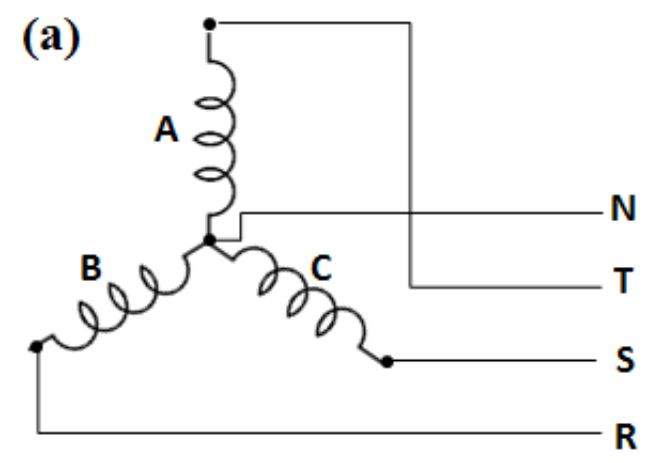

(b)

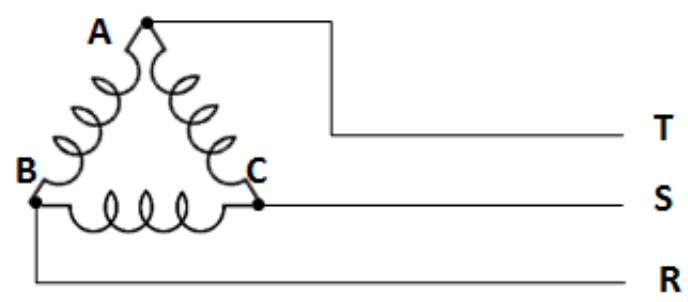

Fig. 5 - Esquema das ligações (a) em estrela, ou $Y$ e (b) da ligação em delta. As letras $A, B$ e $C$ representam as bobinas; $R, S$ e $T$ as fases e, $N$ o neutro. Fonte: Acervo do autor.

\section{Materiais e montagens}

A montagem dos rotores e estatores dos geradores didáticos foram feitos em madeira do tipo MDF (Medium Density Fiberboard) com $6 \mathrm{~mm}$ de espessura. A madeira foi adquirida nas sucatas de uma loja de móveis planejados. Alternativamente, há o acrílico como opção, entretanto, o alto custo e dificuldades em manuseá-lo (com furos e cortes) tornou-se, neste momento, menos prático para as montagens.

Na Fig. 6(a)-(d) encontram-se algumas das etapas da montagem. O rotor em (a), após ser cortado em formato circular, com o uso de uma serra tico-tico, teve seu centro demarcado. Com um lápis, linhas foram traçadas com intersecções passando pelo centro do rotor, fazendo um certo ângulo entre elas, dependendo da quantidade de ímãs e bobinas utilizados. Na parte (b) foi feito um furo no centro do rotor, utilizando uma furadeira de bancada e uma broca chata de 7/8 de polegada de diâmetro, no qual posteriormente foi encaixado um rolamento modelo NSK 608. Na parte (c) são mostrados os ímãs sendo colados com cola do tipo tek

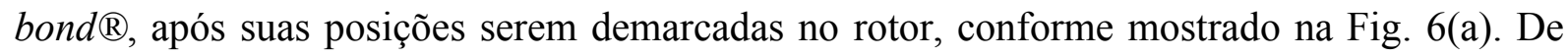
forma análoga, o estator foi construído.

Na Fig. 6(d) está representada a etapa final da montagem, no qual as bobinas foram coladas sobre a borda dos furos, feitos com a broca chata, para garantir que o fluxo do campo magnético, na parte central das bobinas, fosse através do ar. Os ímãs utilizados foram os de neodímio modelo N35 com dimensões 30x3 mm. As bobinas foram enroladas manualmente em um carretel construído no laboratório. Um número de 100 voltas foi feito em cada bobina com fio de cobre esmaltado com bitola AWG 23. A indutância de $(0,20 \pm 0,01) \mathrm{mH}$ em cada bobina foi utilizada como parâmetro de equivalência entre elas.

O sistema bancada didática para o estudo dos geradores está mostrado na Fig. 7. À esquerda desta figura está um dimmer e, um motor universal adquirido em um ferro velho. 
Este foi utilizado inicialmente para variar a tensão e, portanto, a rotação do motor. Uma polia foi cuidadosamente acoplada no eixo do motor no qual foi colocada uma correia. Esta correia foi passada por outra polia, colada sobre o centro do rotor de cada gerador estudado. Veja o APENDICE I para maiores detalhes de montagem.

Na parte direita da Fig. 7 está o estator, no qual plugues pretos e vermelhos foram fixados para a conexão dos terminais de cada bobina. $\mathrm{O}$ estator foi preso por meio de uma barra roscada de $7 \mathrm{~mm}$ de diâmetro nos quais porcas de fixação foram rosqueadas. A barra roscada foi usada como eixo central no qual o rotor (não mostrado) gira sobre o estator. Embora outra fonte pudesse ter sido utilizada para colocar o gerador em funcionamento (vento ou queda d'água) o motor, é a melhor maneira, para se manter uma rotação constante, o que tornou o experimento mensurável. O dimmer utilizado para este fim, não foi capaz de manter a rotação constante em intervalos de tempo suficiente para a coleta de dados. Ele foi substituído por uma fonte de tensão alternada variável que alimentava diretamente o motor.
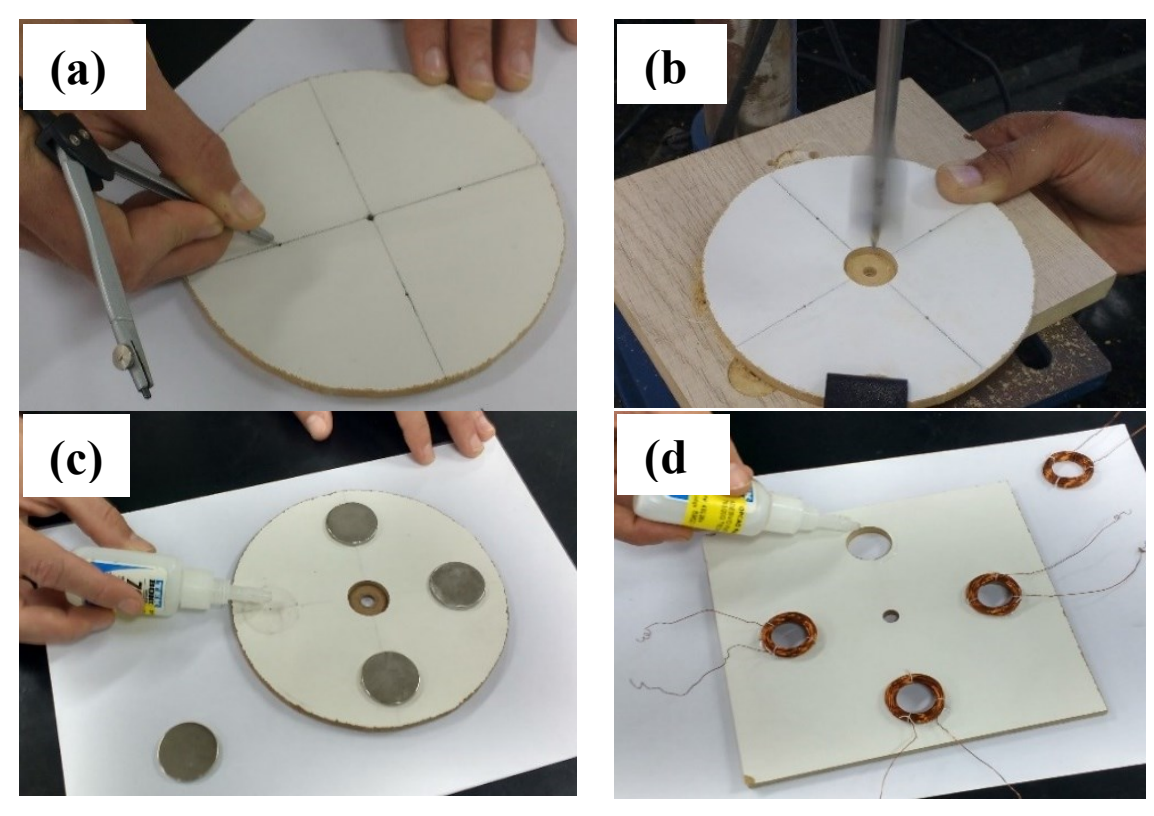

Fig. 6 - De (a) - (c) partes da montagem do rotor e em (d) montagem do estator. Fonte: Acervo do autor.

Um osciloscópio digital modelo Minipa MO 2000 foi utilizado para a medição das amplitudes de tensão das ondas geradas pelos geradores. Multímetros do tipo true RMS foram utilizados para a medição de valores eficazes. Estes são adequados, pois medem os valores eficazes verdadeiros, mesmo quando as ondas não são senoidais. 


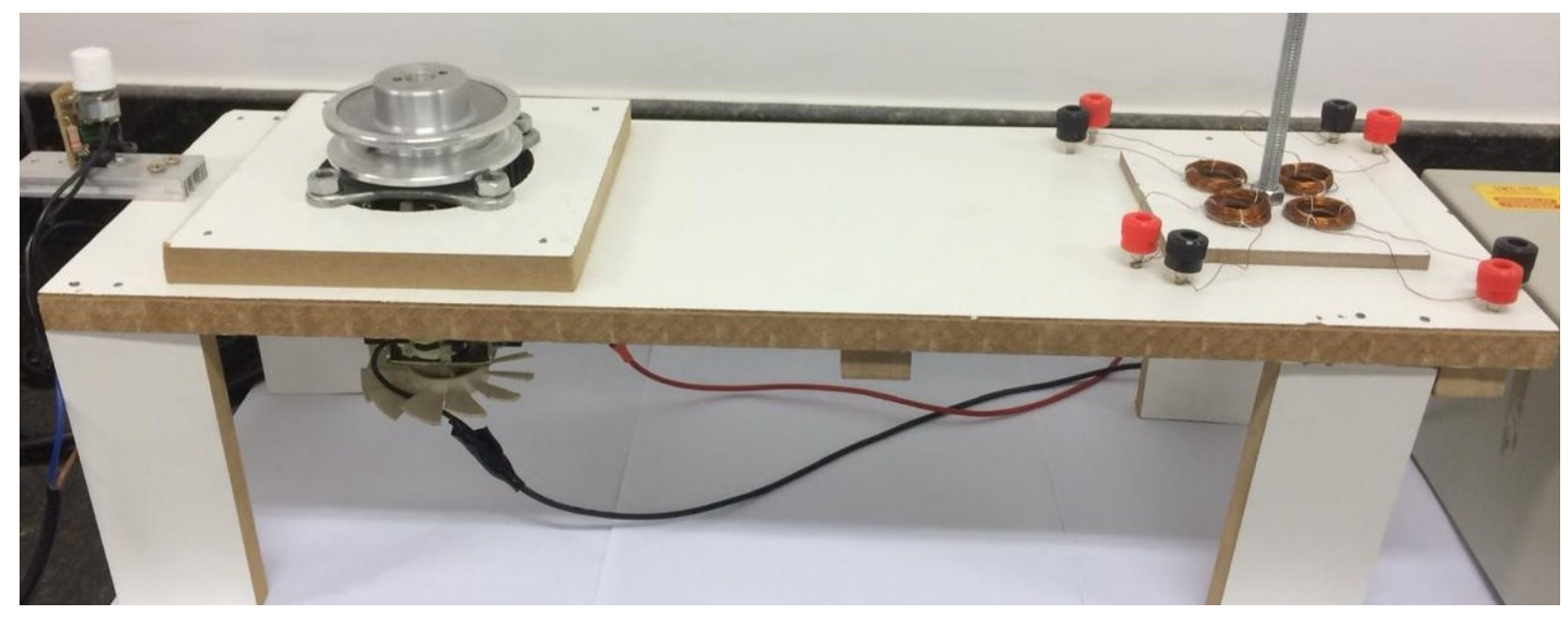

Fig. 7 - Sistema montado para o estudo dos geradores. Fonte: Acervo do autor.

\section{Atividades propostas e resultados}

\section{IV.1 Sistemas monofásicos}

Nas Fig. 8(a)-(b) estão apresentados o rotor e o estator de um gerador monofásico com $\mathrm{N}=4$ polos e quatro bobinas. Em (a), a distância entre os ímãs no rotor é a mesma que as bobinas no estator e equivalem a 3,5 cm. Quando o sistema foi montado, a distância vertical de proximidade entre os ímãs e bobinas, não excedeu os $3 \mathrm{~mm}$. Na parte (b), A e B representam os terminais das bobinas e $\mathrm{T} 1$ e $\mathrm{T} 2$ representam os terminais de saída das bobinas no estator. Nas partes (c) e (d) desta figura, encontra-se o aparato experimental em funcionamento. Um tacômetro digital óptico modelo DT2234C foi utilizado para medir a frequência mecânica $\left(f_{m}\right)$, em RPM do gerador.

Antes de iniciar as medições, o professor pode questionar ao estudante, como devem ser as ligações nas bobinas e, então, mostrar pelo menos duas possibilidades. Na Fig. 8(c) uma onda do tipo senoidal pode ser vista na tela do osciloscópio quando a ligação entre as bobinas na Fig. 8(b) é feita ao conectar-se A:A e B:B. A rotação no tacômetro indica $\mathrm{f}_{\mathrm{m}} \approx 968$ RPM. A escala de tensão é de $1,00 \mathrm{~V}$ e a leitura na tela indica uma amplitude de tensão $\approx 1,5$ V. Por outro lado, quando a ligação é feita conectando-se A:B (Fig. 8(d)), o que pode ser intuitivo para o estudante por se tratar de uma ligação do tipo fim com início de bobinas, apenas um sinal ruidoso com amplitude $\approx 200 \mathrm{mV}$ é observado no osciloscópio (obs: $\mathrm{f}_{\mathrm{m}} \approx 955$ RPM é da mesma ordem de grandeza). Assim, como discutido na seção II.1, o professor pode explicar porque as ligações do tipo A:A e B:B, devem ser utilizadas, abordando a lei de Faraday/Lenz e apontando a polaridade da tensão em cada bobina. No APENDICE II encontram-se duas experiências simples, voltadas para estudantes no ensino médio. 

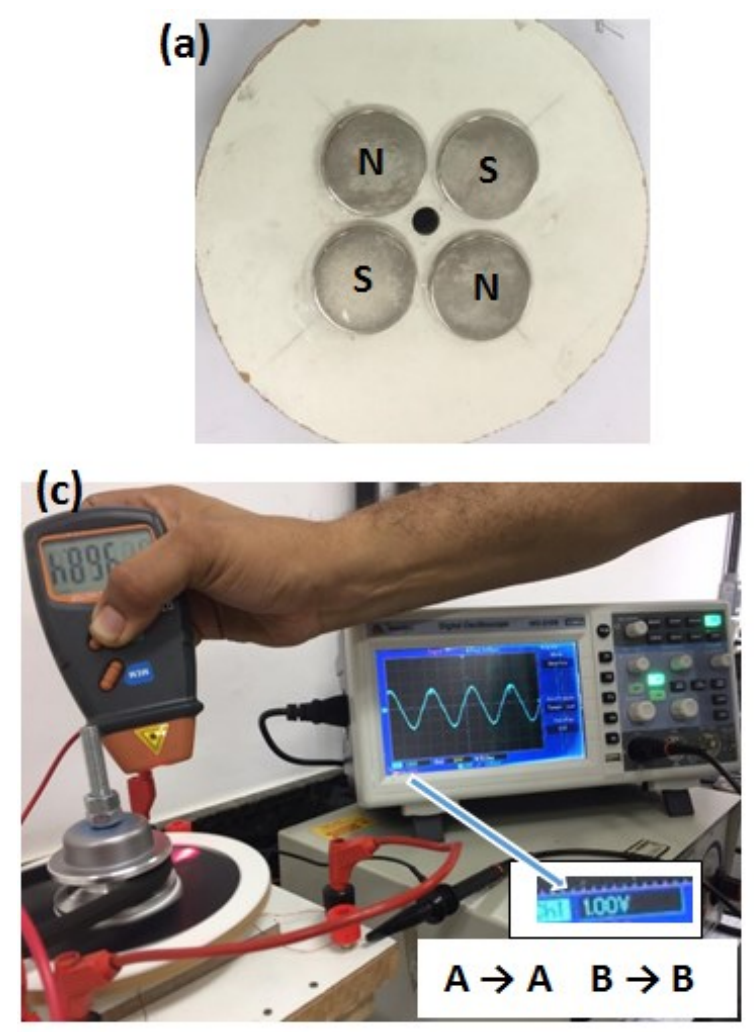
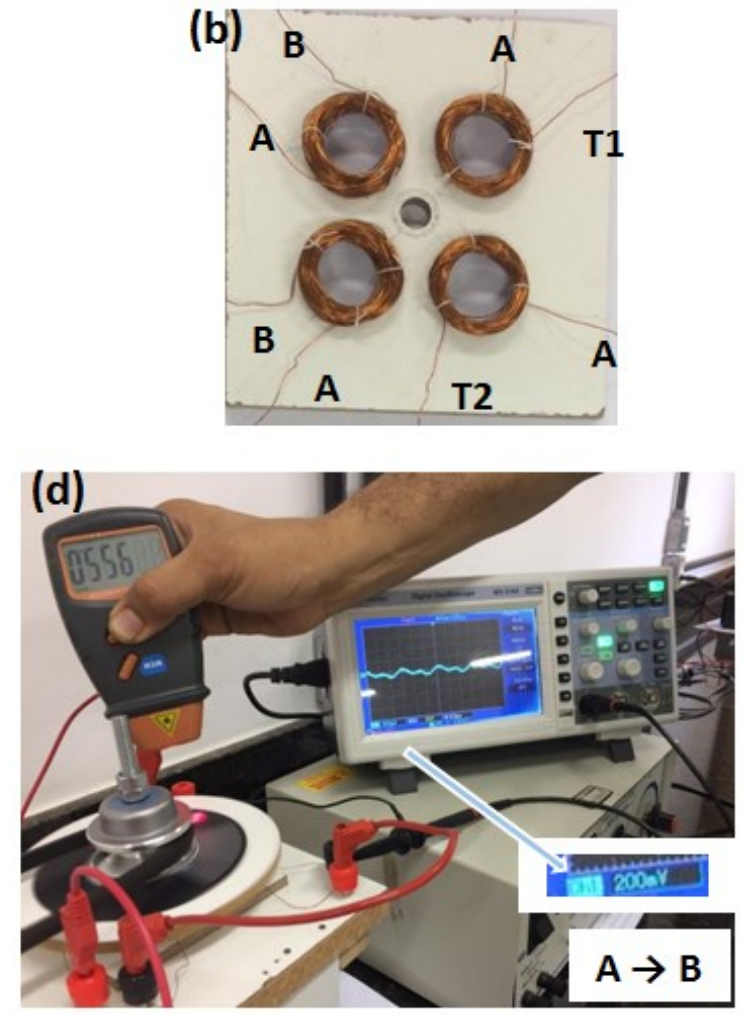

Fig. 1 - (a) Rotor e (b) estator para um sistema monofásico de 4 polos. A, B, T1 e T2 são os terminais das bobinas. Em (c) onda senoidal observada no osciloscópio para uma $f_{m} \approx$ 968 RPM e ligação A:A e B:B entre as bobinas. Em (d) apenas um sinal ruidoso é observado quando a ligação é do tipo A:B. Fonte: Acervo do autor.

\section{IV.1.1 Relação da frequência elétrica $\left(f_{e l}\right)$ e da tensão eficaz $\left(V_{R M S}\right)$ com a frequência mecânica $\left(\mathbf{f}_{\mathrm{m}}\right)$}

Ante ao estudo proposto, foram construídos geradores monofásicos de $\mathrm{N}=4,6,8 \mathrm{e}$ 10 polos (com igual número de bobinas) para o estudo da relação entre a $f_{\text {el }}$ e a $f_{m}$ e, verificação experimental da Equação (4). Os estudos foram feitos em uma faixa de $\mathrm{f}_{\mathrm{m}}$ 's $\approx$ 1000 - 2400 RPM $(16,7$ - 40,0 Hz). Para todos estes geradores, a função de onda foi similar à obtida na Fig. 8(c). Na Fig. 9(a)-(d) estão representados os gráficos de $\mathrm{f}_{\mathrm{el}}$ em função da $\mathrm{f}_{\mathrm{m}}$ (em vermelho), juntamente aos gráficos de $\mathrm{V}_{\mathrm{RMS}}$ em função da $\mathrm{f}_{\mathrm{m}}$, para cada configuração de polos. Os gráficos em azul foram calculados de acordo com a Equação (3): $V_{R M S}=V_{m} / \sqrt{2}$, para comparação com os valores eficazes medidos pelos multímetros (gráficos em preto). No canto superior esquerdo de cada figura, estão apresentadas as fotos dos rotores e estatores de cada gerador em estudo.

Os melhores ajustes foram realizados utilizando o programa Origin pro 8.0 (ORIGINLAB, 2009). Os dados obtidos indicaram que a função que melhor se adequou aos pontos experimentais em todos os estudos foi uma reta. Os coeficientes angulares das retas que descrevem a relação entre $f_{\mathrm{el}}$ e $f_{\mathrm{m}}$ são indicados por ' $\alpha$ ' e a relação entre $V_{\mathrm{RMS}}$ verdadeiros 
(obtidos com o multímetro) e $\mathrm{f}_{\mathrm{m}}$ são indicadas por ' $\theta$ '. Assim, foi observado que os valores de $\alpha$ estão em excelente concordância com a Equação (4): se $\mathrm{N}=4$, por exemplo (Fig. 9(a)), a $f_{\mathrm{el}}$ deve ser duplicada, e o valor $\alpha=2,05 \pm 0,02$ está de acordo com o esperado. O estudante pode verificar para os demais casos que esta relação está em plena concordância.

Foi possível observar, a partir destes gráficos, que houve um aumento nos valores de $\theta$ com o $\mathrm{N}$, chegando próximo aos $20 \mathrm{~V}$ para $\mathrm{f}_{\mathrm{m}} \approx 2300 \mathrm{RPM}$. O estudante pode fazer uma analogia com o caso de pilhas em série: quanto maior o número de pilhas (para este sistema, bobinas e ímãs), maior a tensão gerada. Por outro lado, verificou-se que os valores teóricos de $\mathrm{V}_{\mathrm{RMS}}$ obtidos a partir da Equação (3), embora próximos, são superiores aos valores verdadeiros obtidos com o multímetro true RMS. Isto se explica, pois, as funções de onda observadas no osciloscópio, tinham forma "entre uma onda triangular e uma senoidal". Ondas deste tipo podem ser descritas como uma soma de ondas harmônicos senoidais e os valores de $\mathrm{V}_{\mathrm{RMS}}$ não seguem à risca, a Equação (3).
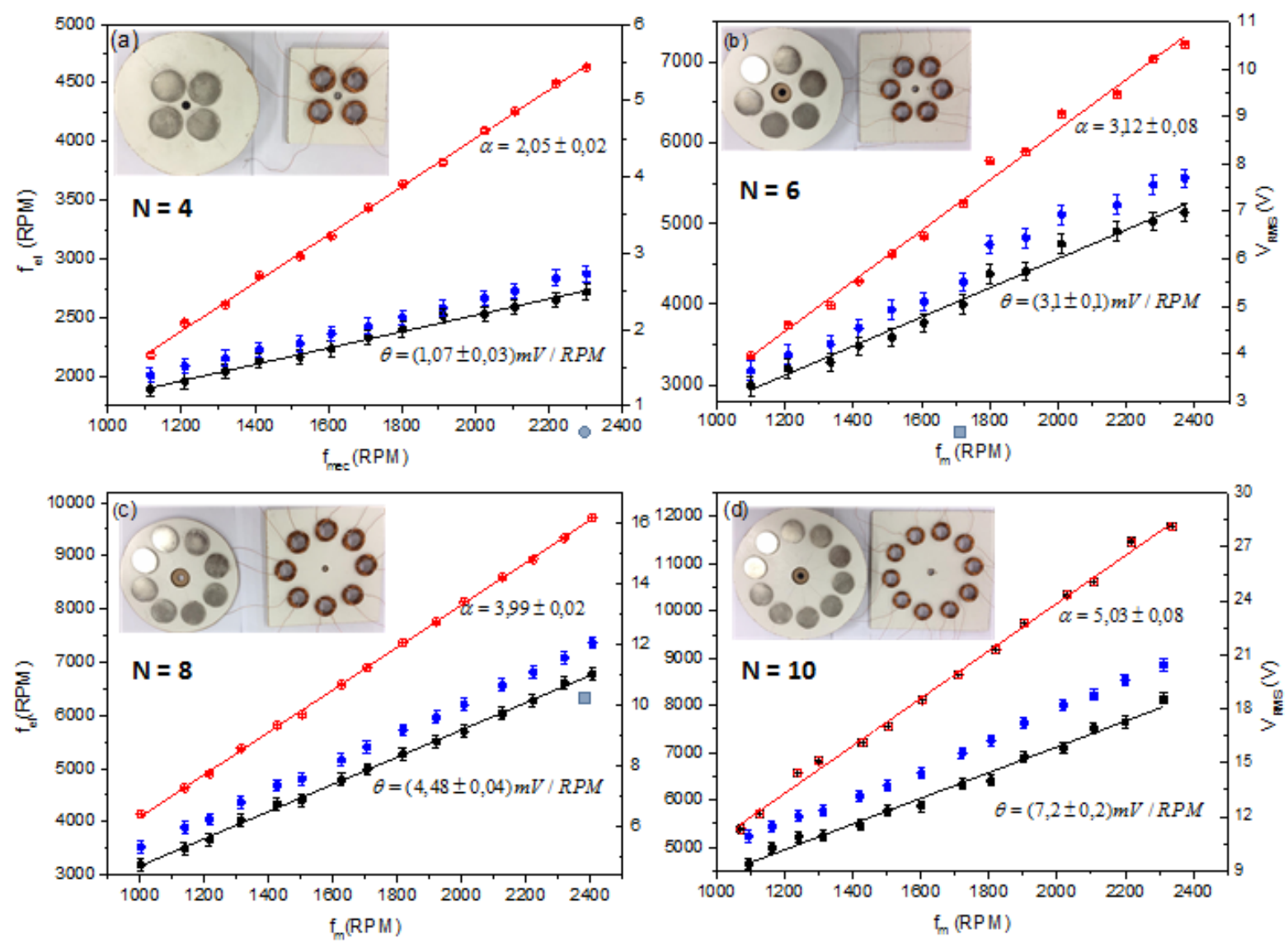

Fig. 9 - Em vermelho, a variação da frequência elétrica $\left(f_{e l}\right)$ em função da frequência mecânica $\left(f_{m}\right)$ para os geradores monofásicos com número de polos $(N)$ iguais a (a) 4, (b) 6, (c) 8 e (d) 10. Os gráficos em azul e preto representam os valores teóricos da tensão eficaz e os obtidos com o multímetro true $R M S\left(V_{R M S}\right)$. As letras $\alpha$ e $\theta$ representam as inclinações das retas de $f_{e l}$ e $V_{R M S}$ respectivamente. Fonte: Acervo do autor. 


\section{IV.1.2 Variação da forma de onda com a distância entre os ímãs}

Na Fig. 10(a)-(d) estão apresentadas as formas de onda para o sistema monofásico com 4 bobinas/polos, para as distâncias de $3,5 \mathrm{~cm}, 5,0 \mathrm{~cm}, 7,0 \mathrm{~cm}$ e $10,0 \mathrm{~cm}$ entre os ímãs/polos respectivamente. No canto inferior direito de cada figura estão as fotos dos rotores e estatores construídos, com as respectivas distâncias entre os ímãs. A menor distância entre os ímãs foi a que favoreceu a uma forma de onda que mais se assimilou ao de uma senoidal. Foi observado que, ao se afastar os ímãs, surgia entre os picos e os vales, diferentes formas de oscilações. Estas oscilações surgem devido às diferentes configurações de campo magnético existente quando se varia a distância entre os ímãs.

Azevedo et al. (2017) observaram que ao se modificar a configuração de ímãs, apareciam formas de onda semelhantes aos da Fig. 10. Os autores ainda mostraram que a potência elétrica dissipada em um resistor foi maior para ondas que se assemelhava a senoidal e, portanto, com menor quantidade de harmônicos. Por outro lado, não apenas as configurações dos ímãs alteraram as formas de onda, mas também a distância entre eles, como foi observado dos estudos aqui realizados. Desta forma, a distância entre os centros dos ímãs deve ser pelo menos de valores entre de 3,5-4,0 cm para que a forma de onda se assemelhe à senoidal.
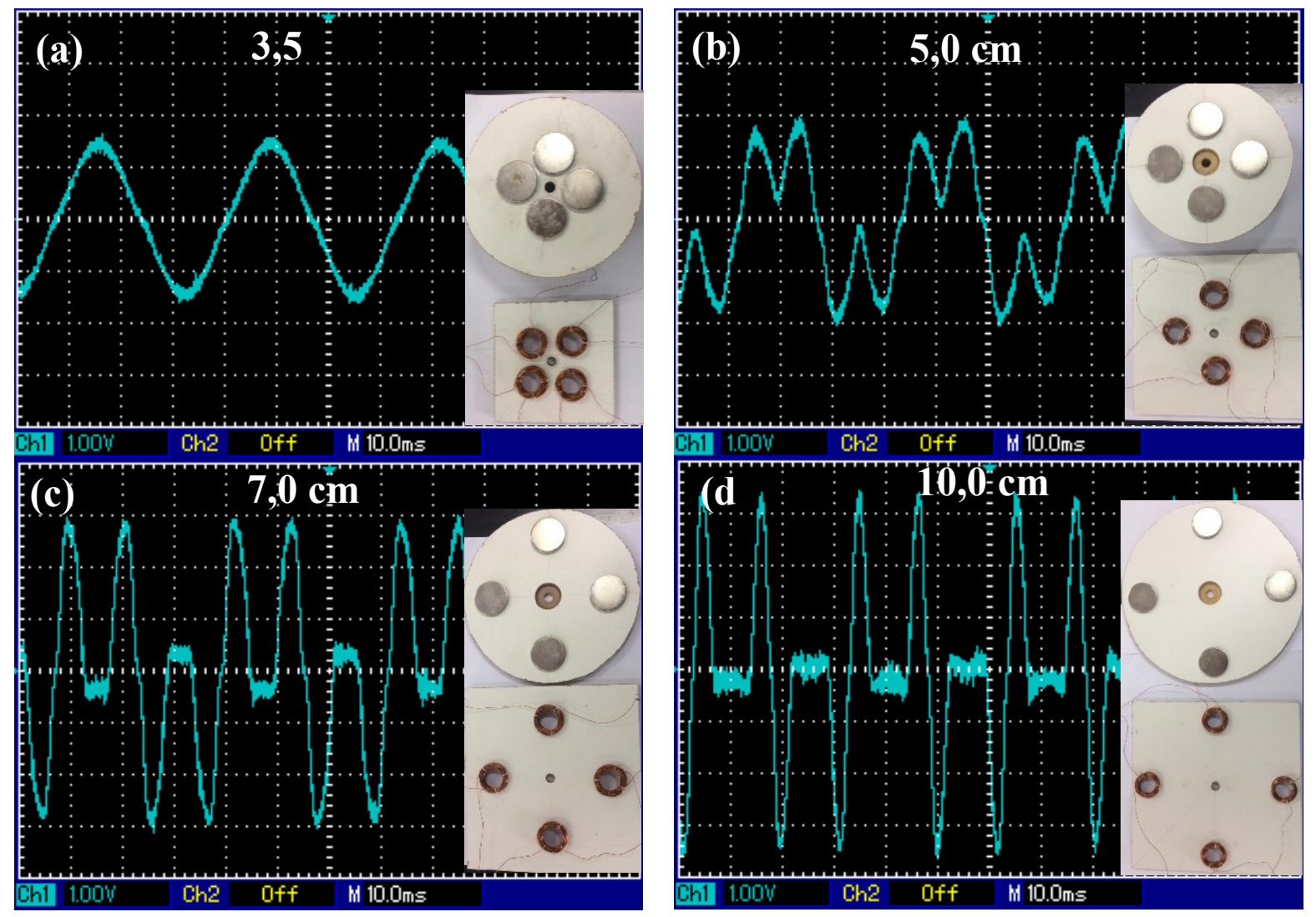

Fig. 10 - Sistemas monofásicos com quatro ímãs/bobinas. A distância entre a parte central dos ímãs foi variada para (a) $3,5 \mathrm{~cm}$, (b) $5,0 \mathrm{~cm}$, (c) $7,0 \mathrm{~cm}$ e (d) $10,0 \mathrm{~cm}$. No canto direito de cada figura, os respectivos rotores e estatores utilizados. Fonte: Acervo do autor. 


\section{IV.2 Sistemas trifásicos}

No sistema trifásico, foram construídos geradores com configurações de 3, 6 e 9 bobinas. Para melhor entendimento da prática experimental, sugere-se ao estudante realizar uma revisão das ligações do tipo estrela $(\mathrm{Y})$ e delta $(\Delta)$, utilizadas neste sistema (seção II.3). Na Fig. 11(a)-(c) encontram-se os rotores e estatores para cada sistema trifásico em estudo. Como será discutido, cada configuração requer conjuntos diferentes entre bobinas e ímãs.
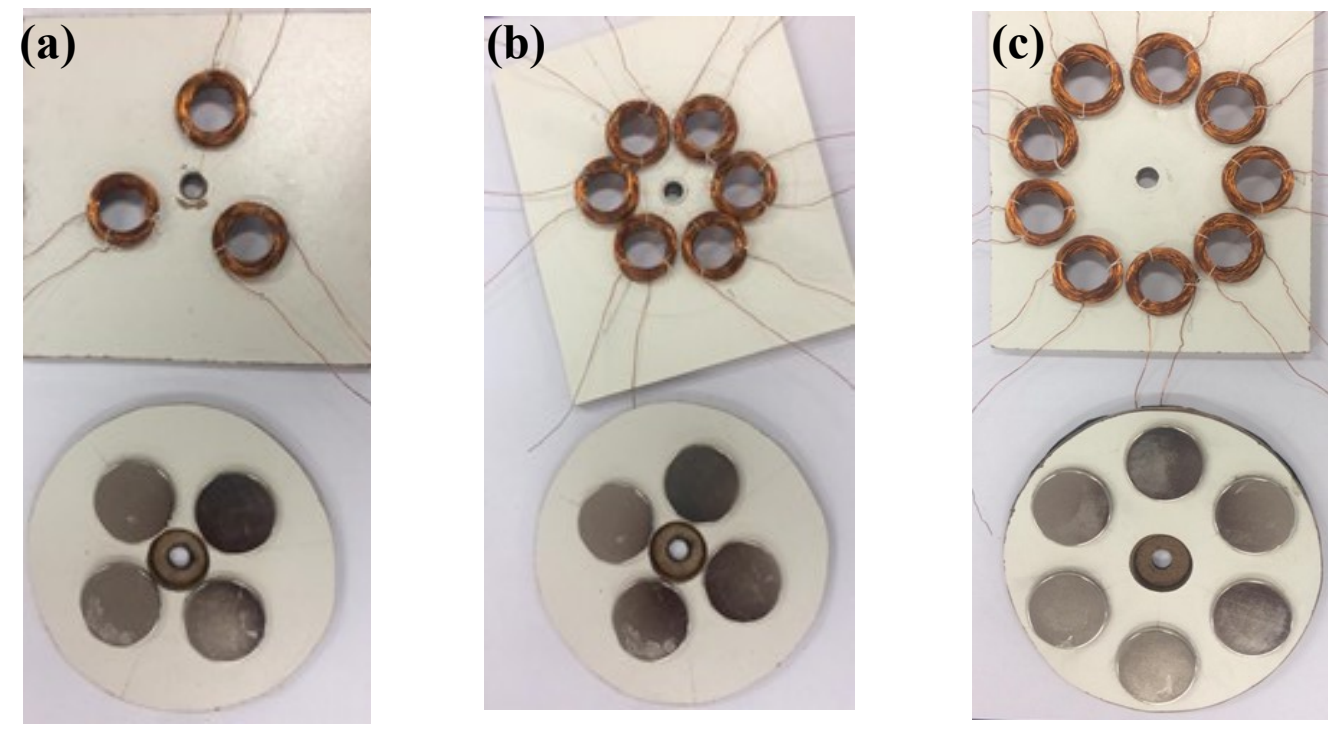

Fig. 11 - Na parte superior estão as bobinas dos estatores e, na parte inferior os rotores, para os sistemas com (a) três, (b) seis e (c) nove bobinas. Fonte: Acervo do autor.

Nas Fig. 12(a)-(b) estão apresentados dois geradores, sendo um de 3 bobinas e 2 polos e o outro de 6 ímãs e 4 polos. Os ímãs foram ilustrados na frente das bobinas, apenas para facilitar a abordagem que será feita. A Fig. 12(a) é semelhante à Fig. 3(a) e foi colocada aqui apenas para fins comparativos com o gerador de 6 bobinas da Fig. 12(b). No sistema com 6 bobinas, a defasagem entre elas é de $60^{\circ}$ e para os ímãs, de $90^{\circ}$. As linhas coloridas representam uma ligação do tipo estrela. A, B, C, A', B' e C' são as bobinas e n, representa o neutro.

O estudante pode se perguntar: numa ligação com 6 bobinas, basta ligar as bobinas vizinhas em série, tipo $\mathrm{C}^{\prime}: \mathrm{B}, \mathrm{A}^{\prime}: \mathrm{C}$ e $\mathrm{B}^{\prime}: \mathrm{A}$ e tratar cada bobina desta, como uma única? Embora esta ligação pareça mais simples e intuitiva, a resposta é não. Esta não é a configuração que maximizará a tensão elétrica no sistema e, portanto, não será aquela que produzirá a tensão desejada. É importante, portanto, que o estudante tenha a seguinte visão: no sistema com três bobinas da Fig. 12(a), o polo norte está passando sobre a bobina B e, o sul está entre as bobinas $\mathrm{C}$ e A. Teoricamente, esta configuração é aquela que irá fornecer tensões descritas nas Equações (4)-(6) e possibilitando um neutro. Na Fig. 12(b) os pares de bobinas, ligados em série e que fornecem uma fase, estão indicados por A:A', B:B' e C:C'. O estudante deve ter a percepção de que a mesma situação observada no sistema de três bobinas 
se repete neste sistema de seis bobinas: nas bobinas $\mathrm{B}: \mathrm{B}^{\prime}$ há um polo $\mathrm{N}$ sobre elas enquanto justamente entre C e A' e entre A e C' há um polo S. Esta observação justifica a ligação feita na Fig. 12(b), descrita da seguinte forma: liga-se as extremidades direita de 3 bobinas adjacentes (C', B, A'), para a formação do neutro. Pega-se a extremidade da primeira (C'), saltam-se duas bobinas, ligando em série com a terceira (C) e, assim por diante.
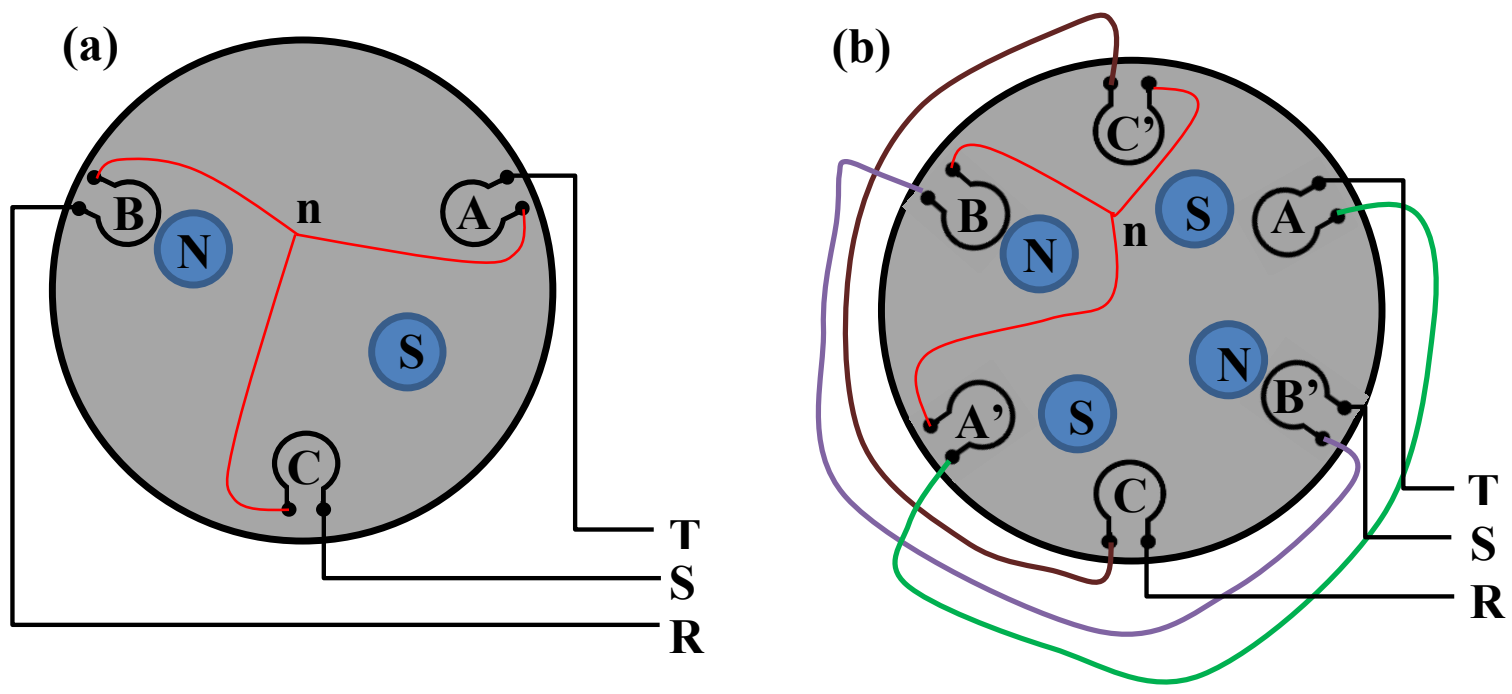

Fig. 12 - (a) Ilustração de um gerador de dois polos (ímãs em azul) e três bobinas. (b) Gerador de quatro polos e seis bobinas. As bobinas são indicadas pelas letras $A, B, C, A$ ', $B$ ' e C'e, a ligação entre elas pelas linhas coloridas, é a do tipo estrela. Fonte: Acervo do autor.

Para um sistema com um número maior de bobinas e ímãs a situação descrita anteriormente deve se repetir. Para isto, é conhecida a relação entre o número de bobinas $\left(n_{b}\right)$ e o número de par de polos $\left(n_{p}\right)$ :

$$
n_{b}=3 n_{p}
$$

Por exemplo, se $n_{p}=3$ pares de polos: $3 \mathrm{~N}$ e $3 \mathrm{~S}$ (6 ímãs), então $n_{b}=9$ bobinas. $\mathrm{A}$ relação entre as frequências, $\mathrm{f}_{\mathrm{el}}$ e $\mathrm{f}_{\mathrm{m}}$, nos sistemas trifásicos, continuam sendo calculadas de acordo com a Equação (4). Uma abordagem mais detalhada é encontrada em MAIA (2011).

Na Fig. 13(a) e (b) encontram-se as ligações esquemáticas em Y e $\Delta$ para um gerador trifásico de seis bobinas e quatro ímãs. A ligação em delta segue um padrão semelhante para a ligação em estrela. A maneira mais fácil de fazê-la nas bobinas do gerador é observando a Fig. 13(b). O estudante pode fazê-la como um exercício, utilizando uma ilustração tipo ao da Fig. 12(b) e olhando as ligações da Fig. 13(a). 

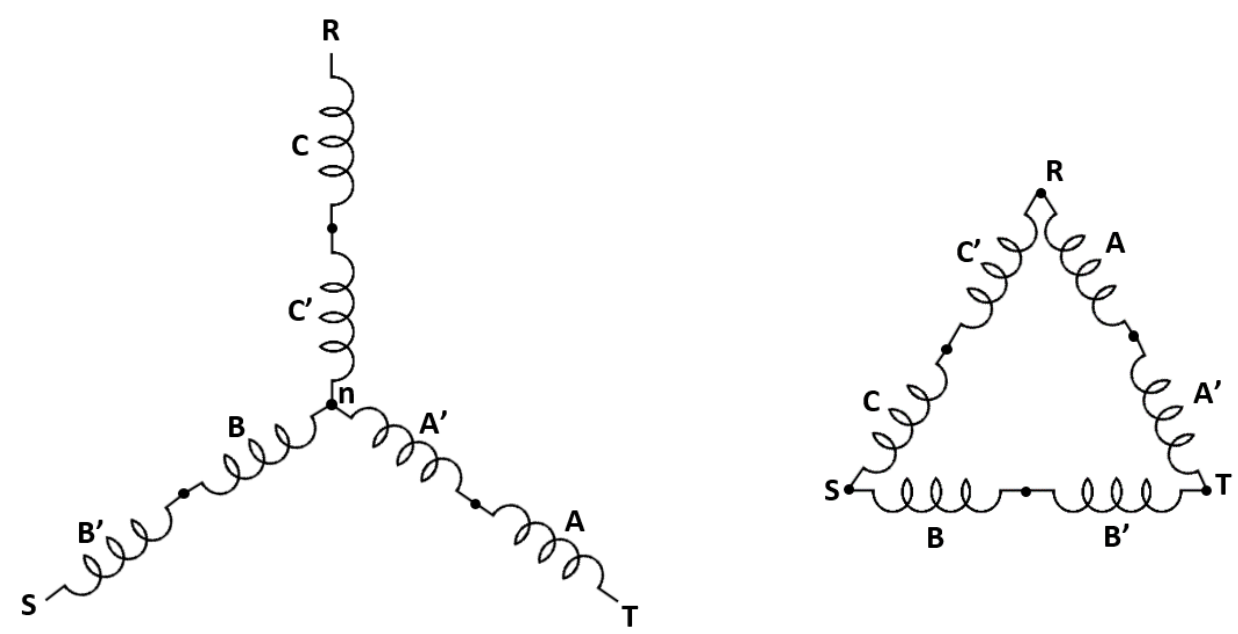

Fig. 13 - (a) Esquema das ligações em (a) estrela e (b) triângulo. Fonte: Acervo do autor.

As formas de onda, obtidas com o uso de um osciloscópio digital de 4 canais, para o gerador de 3 e 9 bobinas (4 e 6 ímãs respectivamente) estão ilustradas na Fig. 14(a) e (b). Ambas as formas de onda foram obtidas para uma rotação, tal que $\mathrm{f}_{\mathrm{m}} \approx 950 \mathrm{RPM}$. As formas de onda foram obtidas com o fio de referência do osciloscópio no neutro e, os demais nas fases. Assim, estas representam as variações nas tensões de fase. Por outro lado, as formas de onda para as tensões de linha (entre duas fases) estão apresentadas na Fig. 14(c) e (d). Para as ondas que representam a tensão de linha, a ponta de prova do osciloscópio foi colocada em uma fase e o ponto de referência em outra. Observou-se que as amplitudes das tensões de linha não são as mesmas e, portanto, trata-se de um sistema não equilibrado, o que pode acarretar em uma pequena corrente no neutro (LENZ, 2013).

Observa-se que assim como no sistema monofásico, a forma de onda não é completamente senoidal, havendo distorções harmônicas. Como prática experimental, pode-se obter a defasagem entre as fases, a partir de uma regra de três simples e observando a escala do tempo na Fig. 14: $10 \mathrm{~ms}$ em (a) e $5 \mathrm{~ms}$ em (b). Por exemplo, na Fig. 14(b), o período (T) de uma fase é $\approx 20 \mathrm{~ms}$ (o que corresponde a $360^{\circ}$ ) e, a defasagem na escala de tempo é de $\Delta \mathrm{t} \approx$ $6,5 \mathrm{~ms}$. Através de uma regra de três simples, obtém-se $\Delta \phi \approx 117^{\circ}$, próximo de $120^{\circ}$. Pode-se medir também a razão entre as amplitudes, considerando a escala vertical. Para o sistema com nove bobinas, por exemplo: $\mathrm{V}_{\mathrm{L}} / \mathrm{V}_{\mathrm{F}} \approx 1,68$ próximo a 1,73 , como requerido no sistema trifásico. As pequenas diferenças observadas entre valores experimentais e teóricos ocorrem devido as ondas geradas não serem senoidais.

Para o estudo da relação entre a tensão eficaz de linha $\left(\mathrm{V}_{\mathrm{L}}\right)$ e de fase $\left(\mathrm{V}_{\mathrm{F}}\right)$, na ligação em Y, foram realizadas medidas com o uso de 3 multímetros True RMS, variando-se a rotação mecânica do gerador (registrada através de $\mathrm{f}_{\mathrm{m}}$ ). Concomitante com estas medições, a relação entre a $f_{e l}$ e a $f_{m}$ foi realizada com o uso do osciloscópio. Os resultados obtidos para a relação entre as tensões, para os sistemas com 3, 6 e 9 bobinas estão mostrados pelos gráficos à esquerda da Fig. 15(a), (b) e (c), respectivamente (em azul e preto). A direita de cada uma 
delas, a relação entre as frequências. As duas retas em cada gráfico de tensão, indicam medições em duas fases diferentes $\left(\mathrm{V}_{\mathrm{L} 1}\right.$ e $\left.\mathrm{V}_{\mathrm{L} 2}\right)$. $\mathrm{O}$ coeficiente angular da reta superior (em azul) e da inferior em preto, são indicadas por $\theta_{1}$ e $\theta_{2}$, respectivamente. Todos os valores obtidos estão na faixa de 1,66 a 1,78, estando em boa concordância para o sistema trifásico (da ordem de 1,73). Adicionalmente, a relação entre as frequências, indicadas por $\alpha$, sugerem que as mesmas foram praticamente duplicadas para os sistemas com 3 e 6 bobinas (ambos 4 polos) e triplicada, para o sistema com 9 bobinas ( 6 polos) estando em boa concordância com a Equação (4).

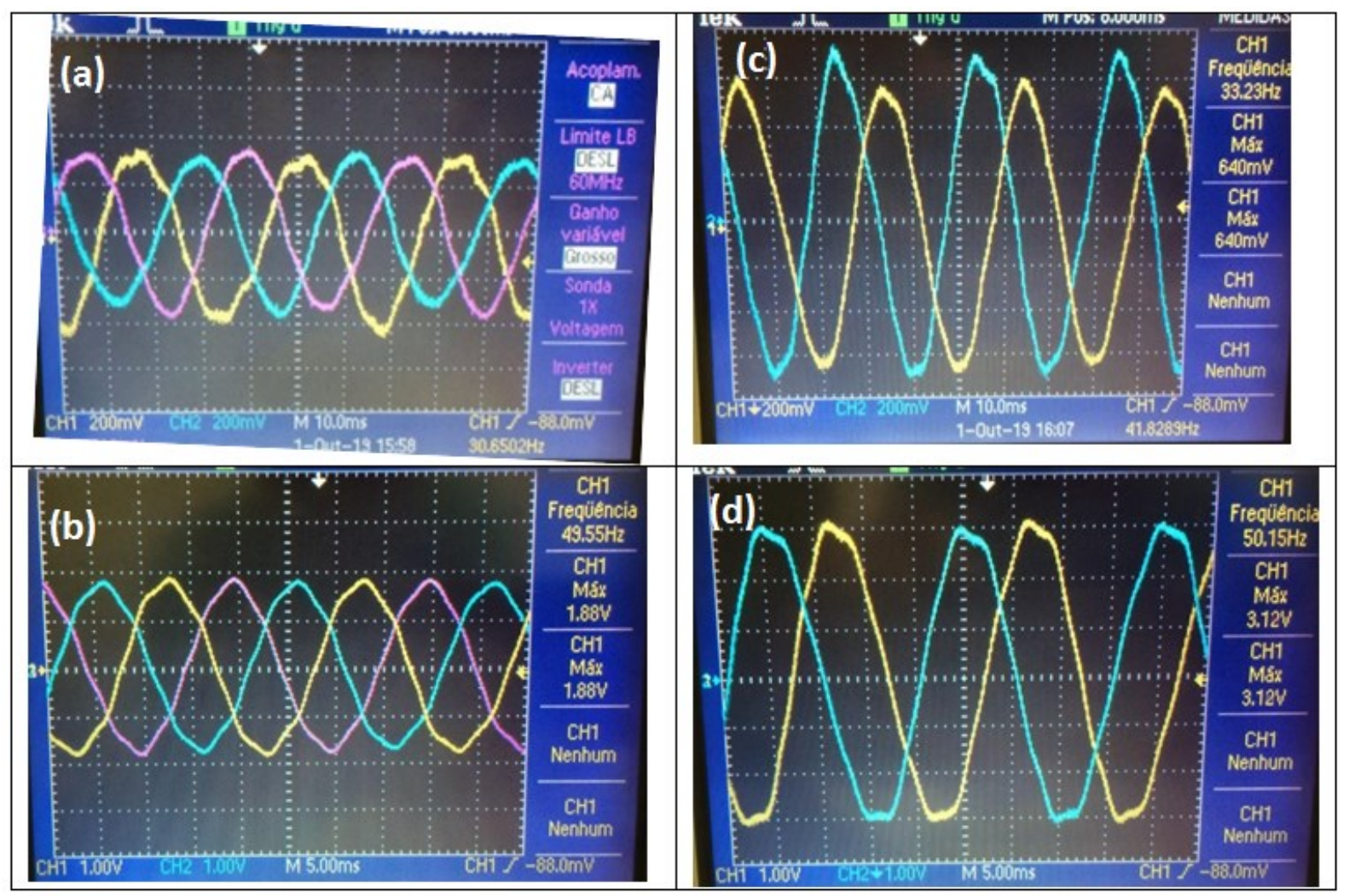

Fig. 14 - Formas de onda obtidas com um osciloscópio de quatro canais para uma velocidade de 950 RPM. Em (a) e (b) sistema trifásico com 3 e 9 bobinas para $N=4$ e 6 polos respectivamente. Em (c) e (d) as respectivas formas de onda para as tensões entre duas linhas. Fonte: Acervo do autor.

O mesmo estudo foi realizado para a ligação em delta nos sistemas com 3, 6 e 9 bobinas. Os resultados estão apresentados na Fig. 16(a)-(c). Como não há neutro neste sistema, a relação das tensões foi medida de duas fases com relação a uma outra. Neste caso, os valores de $\theta_{1}$ e $\theta_{2} \approx 1$ indicam que os valores de tensão eficaz nas 3 fases são equivalentes, como era de se esperar. Por outro lado, os valores de $\alpha$ para este sistema continuam seguindo a mesma sistemática que na ligação em estrela. 

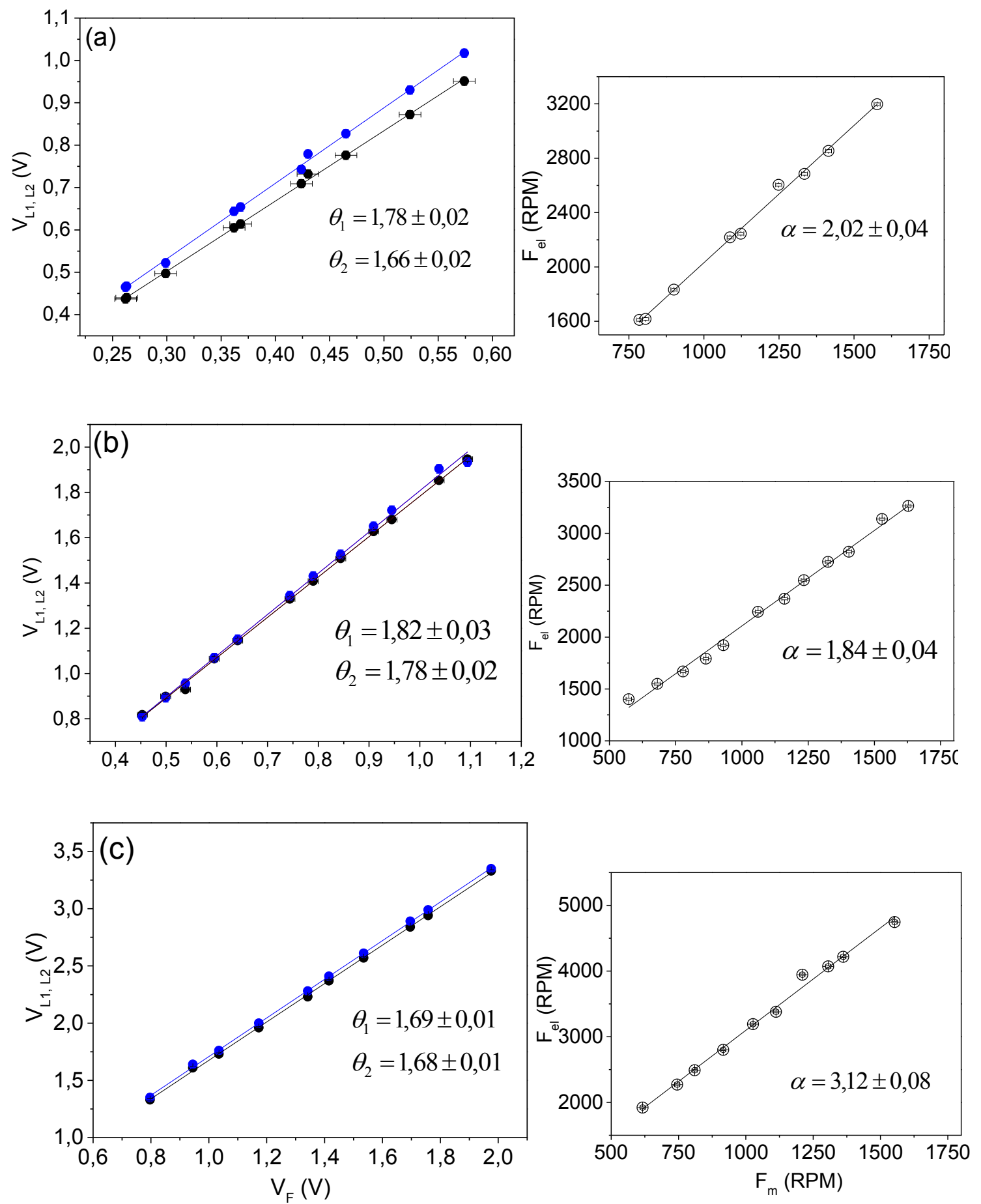

Fig. 15 - À esquerda: relação entre as tensões de linha $\left(V_{L 1}\right.$ e $\left.V_{L 2}\right)$ em função das tensões de fase $\left(V_{F}\right)$ para geradores trifásicos com 3, 6 e 9 bobinas para a ligação em $Y$. Os valores de $\theta_{1}$ e $\theta_{2}(\approx 1,7)$ representam a inclinação das retas em azul e preto respectivamente. À direita, gráficos de $f_{\text {el }}$ em função de $f_{m}$ para os 3 sistemas em estudo. Os valores de $\alpha$ representam as respectivas inclinações das retas. Fonte: Acervo do autor. 

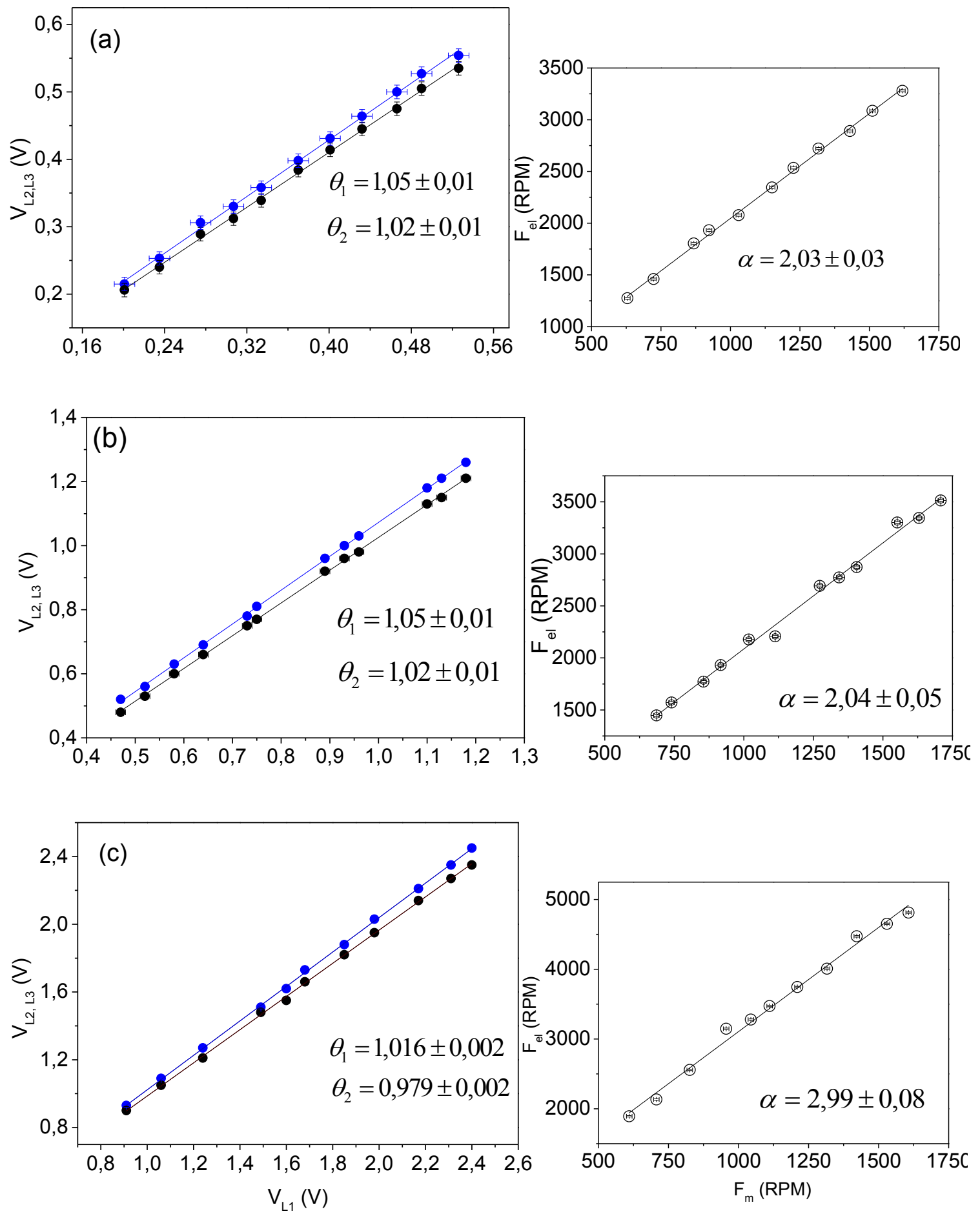

Fig. 16 - À esquerda: relação entre duas das tensões de linha $\left(V_{L 1}\right.$ e $\left.V_{L 2}\right)$ em função da tensão de outra linha escolhida $\left(V_{L 1}\right)$ para geradores trifásicos com 3, 6 e 9 bobinas para a ligação em $\Delta$. Os valores de $\theta_{1}$ e $\theta_{2}(\approx 1,0)$ representam a inclinação das retas em azul e preto respectivamente. À direita, gráficos de $f_{\text {el }}$ em função de $f_{m}$ para os 3 sistemas em estudo. Os valores de a representam as respectivas inclinações das retas. Fonte: Acervo do autor. 


\section{Conclusões}

Neste trabalho foi demonstrado que a construção de geradores elétricos simples, do tipo fluxo axial permite entender a geração da energia elétrica alternada. Inicialmente foi observado que para maximizar a tensão gerada, nos sistemas monofásicos foi preciso utilizar os conceitos da lei de Faraday/Lenz para a conexão das bobinas em série. Foi possível observar que a forma de onda é influenciada pela distância entre os ímãs, pois a configuração do campo magnético no estator é modificada com a distância. A quantidade de ímãs no rotor influencia diretamente na magnitude da tensão gerada e na frequência elétrica do gerador.

Para uma determinada frequência de rotação mecânica foi observado um aumento da frequência elétrica, pela metade da quantidade de polos. Nos sistemas trifásicos foram investigadas as ligações entre as bobinas, a forma de onda gerada e as tensões de linha e fase com a frequência elétrica para sistemas com 3 e 4 bobinas (com 4 polos) e 9 bobinas (6 polos). O sistema convencional de três bobinas e dois polos foi útil para entender, de maneira didática, o sistema com seis bobinas e quatro polos. As formas de onda foram observadas em um osciloscópio digital, no qual foi possível calcular a defasagem entre três formas de onda que se assemelham a uma senoide. Foi possível demonstrar por meio de gráficos que a tensão elétrica (V) no sistema com ligação em estrela, segue uma relação que se aproxima de $\mathrm{V}_{\text {Linha/ }} / \mathrm{V}_{\text {Fase }} \approx 1,73$, característicos de sistemas trifásicos com o neutro. Já na ligação em delta, essa relação se aproxima de 1 , indicando que são geradas três tensões de iguais magnitudes. $O$ kit experimental é fácil e prático de ser construído e, não requer custos elevados.

\section{Trabalhos futuros}

Pretende-se para os sistemas estudados, investigar a influência de materiais magnéticos nos estatores e rotores, sobre a magnitude da tensão gerada. Ainda, obter a potência fornecida pelos geradores, em circuitos resistivos (R), indutivos (L) e capacitivos (C) e, combinação em série RLC, confrontando os dados experimentais com a teoria. Por fim, investigar o fator de potência para geradores monofásicos e trifásicos dos tipos aqui estudados.

\section{Agradecimentos}

Agradecemos à FAPES e à PROGRAD/UFES pelo financiamento deste trabalho e concessões de bolsas de estudo.

\section{Referências}

ALVES, A. L. et al. O ensino de ressonância eletromagnética por um sistema emissor e receptor utilizando o rádio antena de quadro: descrição e análise usando osciloscópio. Física na Escola, v. 17, n. 1, p. 46-52, 2019. 
AZEVEDO et al. Gerador Trifásico de Baixo Custo para o Ensino de Física. Revista Brasileira de Ensino de Física, v. 39, n. 3, e3503, 2017.

BARROSO, M. F.; RUBINI, G.; SILVA, T. Dificuldades na aprendizagem de Física sob a ótica dos resultados do Enem. Revista Brasileira de Ensino de Física, v. 40, n. 4, e4402, 2018.

CARVALHO. G. Máquinas elétricas: teoria e ensaios. 1. ed. São Paulo: Érica LTDA, 2011, $116 \mathrm{p}$.

COSTA, J. R. Uma proposta problematizadora para o ensino do eletromagnetismo sob uma perspectiva histórico-experimental: o Telégrafo. 2016. Dissertação (Mestrado em Ensino de Ciências e Educação Matemática) - Universidade Estadual da Paraíba, Campina Grande.

DIAS, A. C. G.; BARLETTE, V. E.; MARTINS, C. A. G. A opinião de alunos sobre as aulas de eletricidade: uma reflexão sobre fatores intervenientes na aprendizagem. Experiências em Ensino de Ciências, v. 4, n. 1, p.107-117, 2009.

JONNES, J. Empires of light: Edison, Tesla, Westinghouse, and the Race to Electrify the World. New York: Random House, 2004.

ORIGINLAB. Origin 8.1 Getting Started Booklet. Northampton: OriginLab Corporation, 2009. Disponível em:

$<$ https://www.originlab.com/pdfs/Origin_8.1_Getting_Started_Booklet.pdf $>$. Acesso em: 19 out. 2019.

LARA, A. C. Ensino de conceitos básicos de eletricidade através da análise do consumo de energia elétrica na escola. Textos de Apoio ao Professor de Física, Instituto de Física/UFRGS, v. 25, n. 5, 2014.

LENZ, A. L. Veículos elétricos: Máquinas elétricas de ímãs permanentes. Disponível em: $<$ http://automoveiseletricos.blogspot.com/2013/12/maquinas-eletricas-de-imaspermanentes_19.html>. Acesso em: 20 out. 2019.

MAIA, T. A. C. Projeto e construção de um gerador a ímãs permanentes de fluxo axial para turbina eólica de pequena potência. 2011. Dissertação (Mestrado em Engenharia Elétrica) - Universidade Federal de Minas Gerais, Belo Horizonte. 
MARKUS, O. Circuitos Elétricos. 9. ed. São Paulo: Érica, 2004. 122 p. v.1.

MELO, M. G.; CAMPOS, J. S.; ALMEIDA, W. S. Dificuldades enfrentadas por professores de ciências para ensinar física no Ensino Fundamental. Revista Brasileira de Ensino de Ciências e Tecnologia, v. 8, n. 4, p. 241-251, 2015.

MOREIRA, M. A. Grandes desafios para o ensino da Física na educação contemporânea. Revista do Professor de Física, v. 1, n. 1, p. 1-13, 2017.

NAKASHIMA, K. Valor médio e eficaz. Universidade Federal de Itajubá. Instituto de Engenharia de Sistemas e Tecnologias de Informação. Itajubá: UNIFEI/IESTI, 2013. Disponível em: $<$ http://professor.ufabc.edu.br/ jose.azcue/Circuitos\%20Eletricos\%201/rms.pdf $>$. Acesso em: 23 out. 2019.

NIEDERLE, G. D. Turbinas flutuantes: Geradores PMG ou Assíncronos, Acoplamentos e Considerações. Ijuí: Hidroenergia, 2018. Disponível em:

$<$ https://www.hidroenergia.com.br/turbinas-flutuantes-geradores-pmg-ou-assincronosacoplamentos-e-consideracoes/> . Acesso em: 24 out. 2019.

RECHE, E. A.; BREIDI, E.; MARTINS, W. K. A. G. Conversor eletromecânico como ferramenta de aprendizado no Curso de Engenharia Elétrica da UFMT: um trabalho de monitoria. In: CONGRESSO BRASILEIRO DE EDUCAÇÃO EM ENGENHARIA, XLI, 2013, Gramado, RS. Atas...

SADIKU, M. N. O. Fundamentals of eletric circuits. 5. ed. Nova Iorque: Mcgraw Hill, 2013.

WESCHENFELDER, F. et al. Situação atual e perspectivas da produção de ímãs permanentes e reservas de terras raras: Brasil x Mundo. Tecnologia em Metalurgia, Materiais e Mineração, v. 9, n. 4, p. 30 -315, 2012.

YOUNG, H. D.; FREEDMAN, R. A. Física III: Eletromagnetismo. 12. ed. São Paulo: Pearson Education do Brasil, 2009. 204 p. v. 3. 


\section{Apêndice I - Passo a Passo para a Montagem do Aparato Experimental}

Na Fig. 1 está apresentado o aparato experimental. Este é constituído por uma mesa em madeira do tipo MDF, uma polia maior acoplada (tipo A, n. 80) ao eixo de um motor universal (abaixo do aparato), o rotor do gerador contendo os ímãs e polia menor acoplada (tipo A, n. 50), uma correia (goodyear torque flex tipo Z), dimmer (que não foi utilizado) e estator contendo as bobinas e barra roscada $(8 \mathrm{~mm})$.

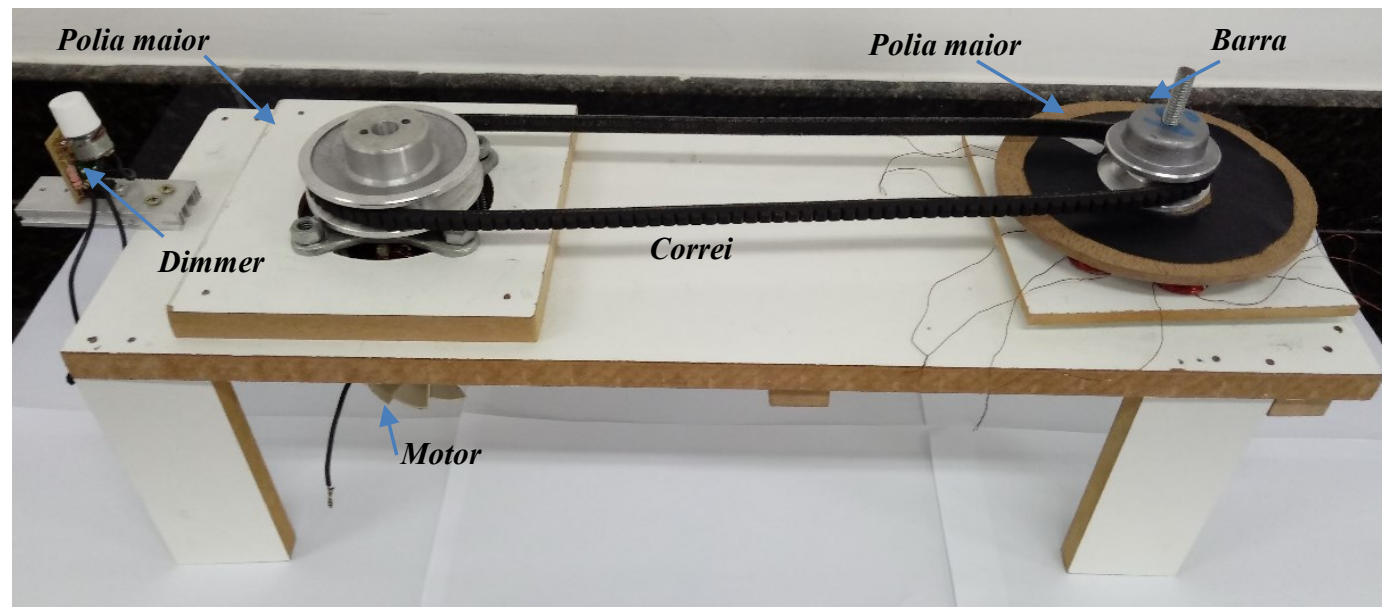

Fig. 1 - Aparato experimental completo.

Na Fig. 2, encontra-se o aparato experimental sem os acessórios. Será mostrado o passo a passo de como este foi montado. O furo para acoplar o motor com a polia foi feito com uma broca com serra do tipo copo. O furo no qual a barra roscada se encaixa (eixo do gerador), foi feito com uma broca de $8 \mathrm{~mm}$. As madeiras foram cortadas manualmente e depois lixadas.

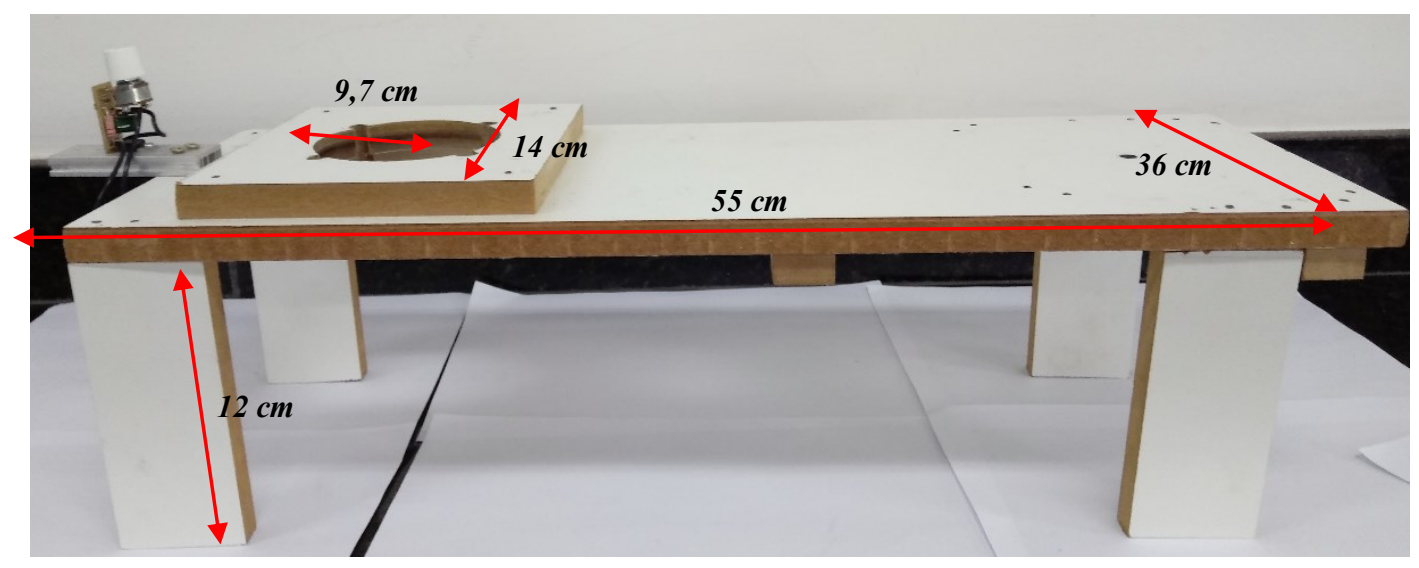

Fig. 2 -Dimensões do aparato experimental sem acessórios. 
Na Fig. 3, é mostrado o aparato apenas com a inclusão da barra roscada. Foram necessárias duas porcas na parte inferior e uma broca na parte superior para prendê-la na mesa do aparato.

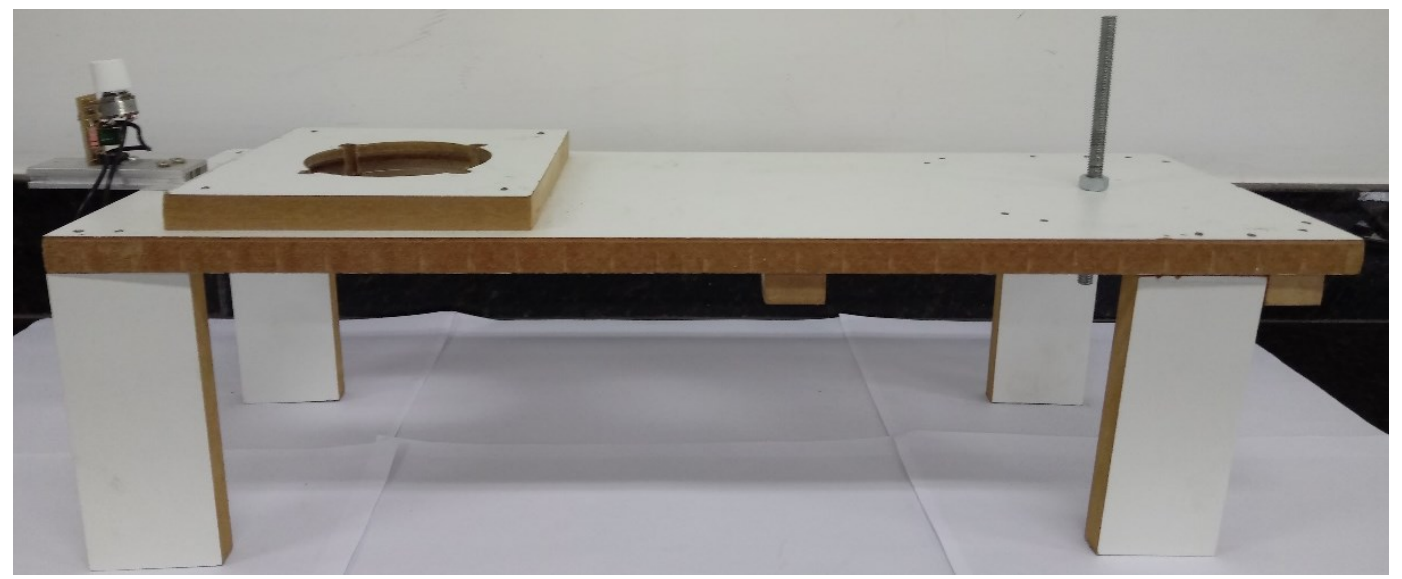

Fig. 3 - Aparato experimental com barra roscada.

Após a inclusão do eixo, basta encaixar o furo do estator na barra roscada (Fig. 4).

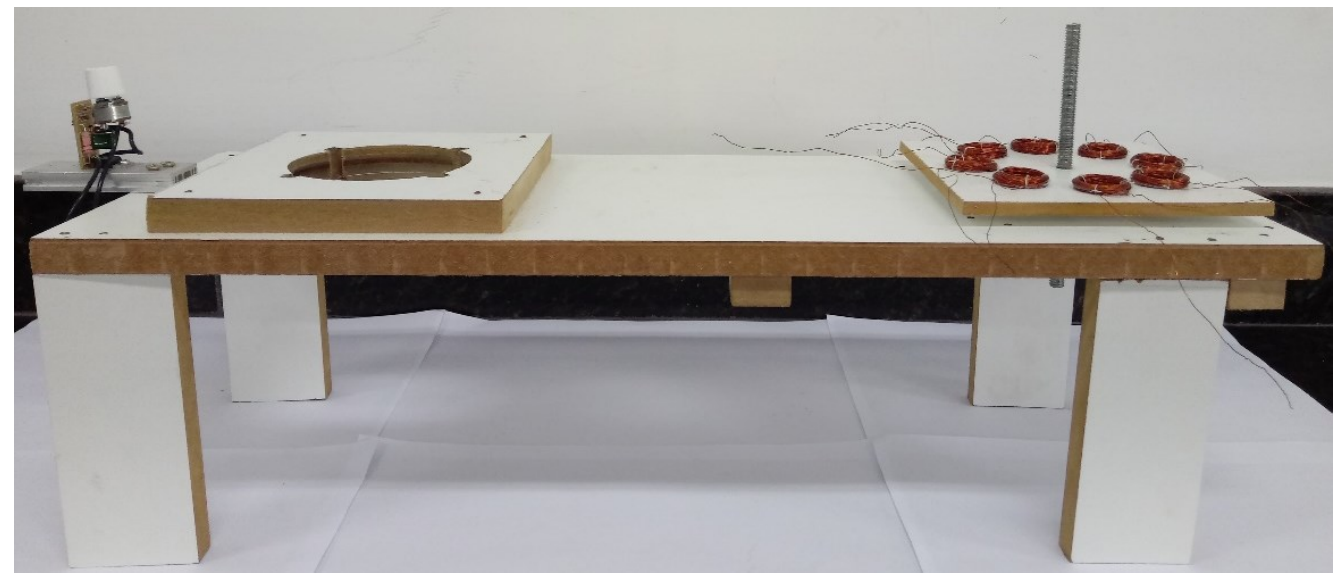

Fig. 4 - Inclusão do estator com bobinas.

Para o encaixe do rotor, com os ímãs, rolamentos acoplados e polia, observe a Fig. 5. A polia e os ímãs foram colados com cola do tipo tec-bond com alta aderência. 


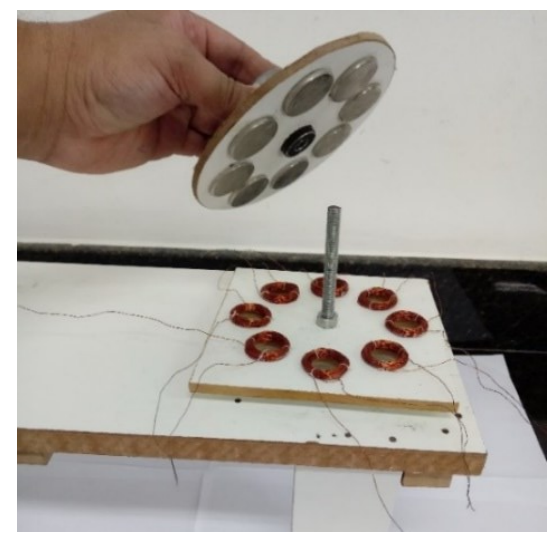

Fig. 5 - Procedimento para inclusão do rotor.

Na Fig. 6, uma vista lateral do sistema, com peças montadas.

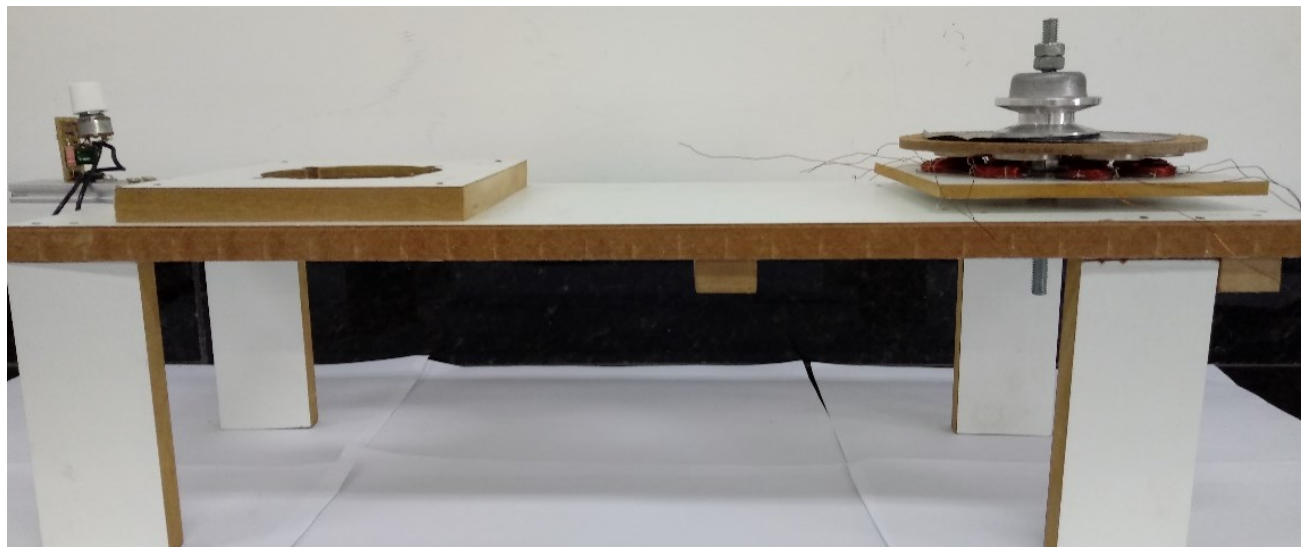

Fig. 6-Vista lateral do sistema.

O motor utilizado para o experimento (Fig. 7) foi o universal modelo HC\&035, 127 V, $60 \mathrm{~Hz}$. Para acoplar a polia, foi necessário um torno mecânico para deixa-lo o mais alinhado possível.

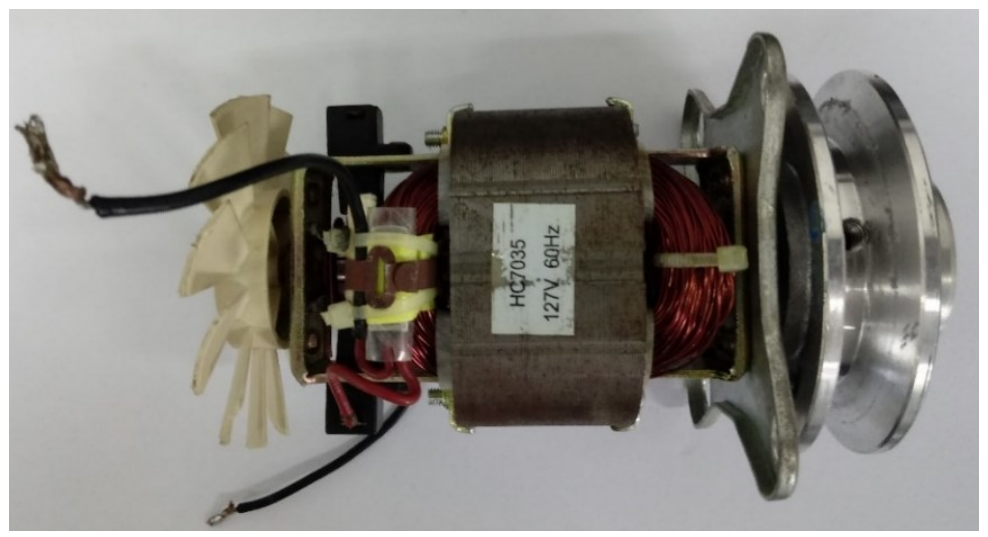

Fig. 7 - Motor universal com polia acoplada ao eixo. 
Maneira de como se deve encaixar o motor com polia, na mesa do aparato experimental (Fig. 8).

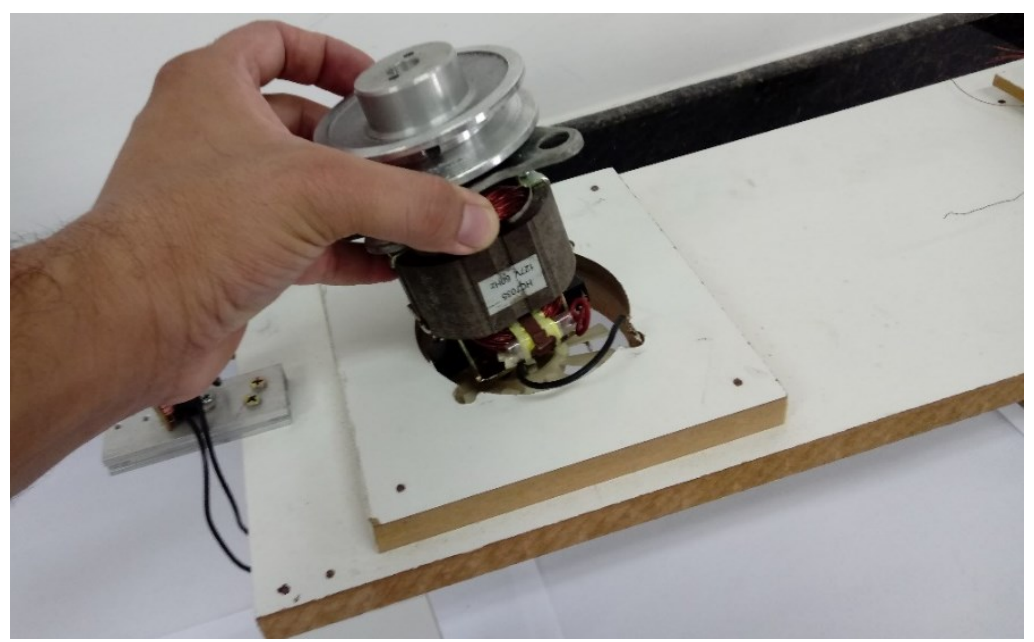

Fig. 8 - Encaixe do motor.

Na Fig. 9 encontra-se o motor encaixado na mesa do suporte. Quatro barras roscadas com porcas prendem a peça de alumínio do motor à mesa do suporte. Para ilustração apenas uma barra roscada com porca é mostrada.

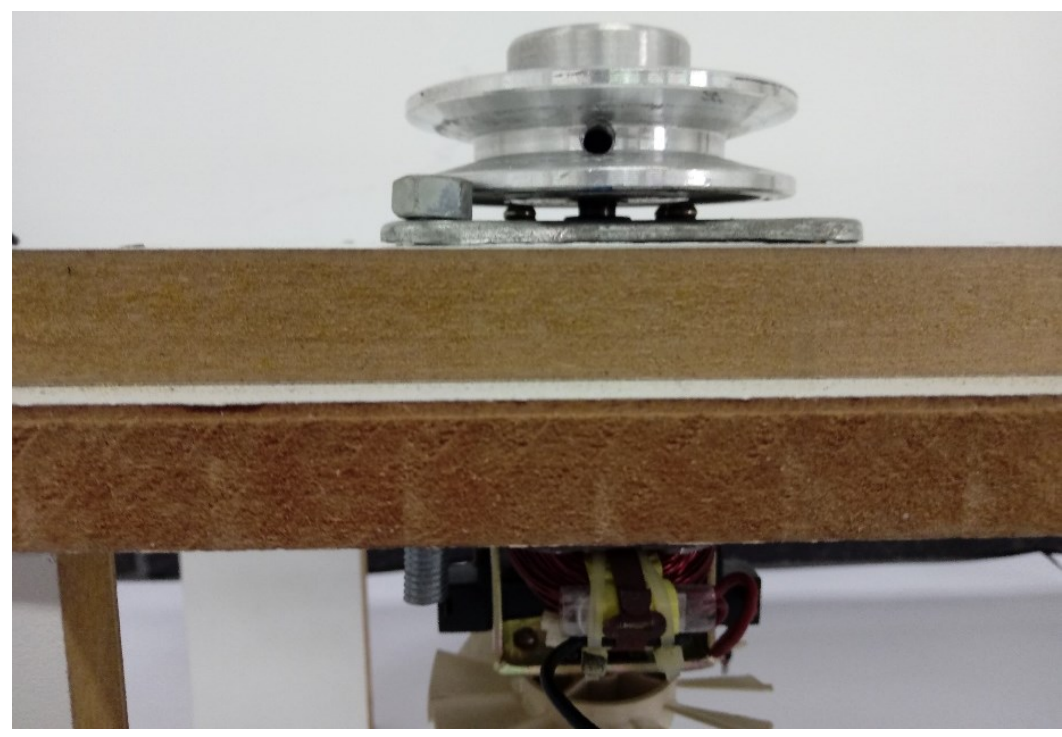

Fig. 9 - Motor encaixado no sistema, preso por meio de barra roscada.

Enfim, o sistema completo com correia (Fig. 10). Agora, basta conectar os terminais do motor no gerador $\mathrm{AC}$ ou $\mathrm{DC}$ e os terminais do gerador no osciloscópio e iniciar as medições. 


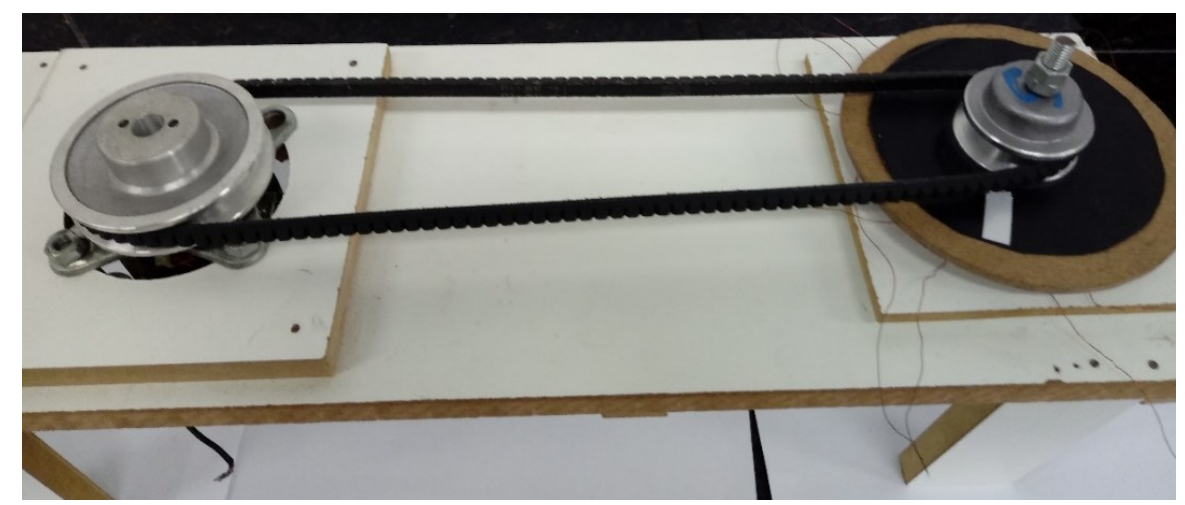

Fig. 10 - Acoplamento de polia. Sistema completo.

\section{Apêndice II - Propostas de experiências para o Ensino Médio}

\section{Experiência I - Gerador monofásico e Lei de Faraday}

\section{Objetivo}

Utilizar a lei de Faraday para entender a conexão entre as bobinas num sistema monofásico. Procedimentos Experimentais

1 - Utilize o sistema de 4 ímas no rotor e 4 bobinas no estator.

2 - Coloque o estator no aparato experimental (Figura 4, APENDICE I), passando pelo eixo central, de tal forma que as bobinas estejam voltadas para cima. Fixe-o com porcas para que este não se mova.

3 - Peça aos estudantes para que façam a ligação entre as bobinas. Intuitivamente, eles podem ligar as bobinas conectando o terminal final de uma delas, com o inicial da bobina vizinha.

4 - Coloque o rotor com rolamentos e polia passando pelo eixo e, com a face que contém os ímãs voltada para baixo (Fig. 5, Apêndice I). Utilize a correia e acople esta polia a polia maior, presa ao eixo do motor.

5 - Ligue este sistema numa rotação "confortável" evitando possíveis vibrações. Conecte os terminais do osciloscópio e analise a forma de onda gerada. Veja que esta não tem a forma de uma função periódica e se assemelha mais a um ruído.

6 - Faça a conexão correta: utilize a lei de Faraday/Lenz considerando o fluxo do campo magnético em cada ímã. Leve em consideração a face do ímã que está passando por cima de uma bobina. Determine o sentido da força eletromotriz em cada bobina e assim, a polaridade nos extremos da bobina.

7 - Faça um desenho esquematizando o procedimento 5 e pergunte aos estudantes como deverá ser feito a ligação correta.

8 - Meça novamente a forma de onda com o osciloscópio. Veja agora que esta forma de onda se assemelha a uma função periódica, típica de uma tensão alternada. 


\section{Experiência II - Frequência Elétrica, Frequência Mecânica e Tensão Eficaz}

Objetivos:

Verificar a relação entre frequência elétrica e frequência mecânica;

Obter a relação entre a amplitude da tensão e a tensão eficaz, comparando valores experimentais com os teóricos.

Procedimentos Experimentais

1 - Repita os passos de $1-4$ da Experiência I, fazendo a conexão entre as bobinas que maximiza a amplitude da tensão. Agora, você pode optar por utilizar o sistema com 6 bobinas e 6 ímãs.

2 - Ligue o sistema e utilize o tacômetro para obter uma determinada frequência de rotação mecânica $\left(\mathrm{f}_{\mathrm{m}}\right)$ de rotação do gerador.

3 - Conecte as pontas do osciloscópio nas extremidades do gerador. Conecte também a um multímetro, para medir valores de tensão eficaz. Ligue o sistema para uma determinada frequência de rotação.

4 - Anote valores de amplitude de tensão $\left(\mathrm{V}_{\text {máx }}\right)$ e período $(\mathrm{T})$ da onda, obtida diretamente da tela do osciloscópio. Repita este procedimento obtendo um total de pelo menos 5 medições. 5 - De posse dos valores de $T$, obtenha a frequência elétrica $\left(f_{e l}\right)$ utilizando a relação $f=1 / T$. OBS: O professor pode juntamente com os estudantes utilizar um programa de computador para fazer um gráfico de $\mathrm{f}_{\mathrm{el}}$ em função de $\mathrm{f}_{\mathrm{m}}$.

7 - Determine a inclinação desta reta. Verifique a quantidade de polos utilizada e explique aos estudantes qual sua relação com a Equação:

$$
f_{e l}=\frac{N}{2} f_{m}
$$

8 - A partir dos valores de $\mathrm{V}_{\mathrm{m}}$ obtidos com o osciloscópio obtenha o valor de tensão eficaz ( $\left.\mathrm{V}_{\mathrm{RMS}}\right)$. Compare, juntamente com os estudantes, com aqueles obtidos diretamente do multímetro.

OBS: Você verá que os valores são próximos. Trabalhe juntamente com os estudantes, explicando por que isto ocorre. 